MS. LIQING PENG (Orcid ID : 0000-0002-0329-2200)

DR. ZHENZHONG ZENG (Orcid ID : 0000-0001-6851-2756)

DR. ZHONGWANG WEI (Orcid ID : 0000-0002-6287-8527)

DR. ANPING CHEN (Orcid ID : 0000-0003-2085-3863)

Article type : Primary Research Articles

\title{
Determinants of the ratio of actual to potential evapotranspiration
}

Running head: Ratio of actual to potential evaporation

\section{Liqing Peng ${ }^{1}$, Zhenzhong Zeng ${ }^{1}$, Zhongwang $\mathrm{Wei}^{2}$, Anping Chen ${ }^{3}$, Eric F. Wood ${ }^{1}$, Justin}

\section{Sheffield $^{4}$}

${ }^{1}$ Department of Civil and Environmental Engineering, Princeton University, Princeton, New Jersey, United States.

${ }^{2}$ River and Environmental Engineering Laboratory, Department of Civil Engineering, University of Tokyo, Tokyo, Japan.

${ }^{3}$ Department of Biology, Colorado State University, Fort Collins, Colorado, United States.

This article has been accepted for publication and undergone full peer review but has not been through the copyediting, typesetting, pagination and proofreading process, which may lead to differences between this version and the Version of Record. Please cite this article as doi: $10.1111 / \mathrm{gcb} .14577$

This article is protected by copyright. All rights reserved. 
${ }^{4}$ School of Geography and Environmental Science, University of Southampton, Southampton, United Kingdom.

*Corresponding author: Liqing Peng, Department of Civil and Environmental Engineering,

Princeton University, Princeton, New Jersey, United States. (lpeng@ princeton.edu)

\section{Keywords:}

Evapotranspiration; Potential evapotranspiration; Leaf area index; Canopy height; Surface conductance; Aerodynamic conductance; Decoupling

\section{Paper type: Primary Research}

\section{Abstract}

A widely-used approach for estimating actual evapotranspiration (AET) in hydrological and earth system models is to constrain potential evapotranspiration (PET) with a single empirical stress factor ( $\Omega=$ AET $/ \mathrm{PET}$ ). $\Omega$ represents water availability and is fundamentally linked to canopy-atmosphere coupling. However, the mean and seasonal variability of $\Omega$ in the models have rarely been evaluated against observations, and the model performances for different climates and biomes remain unclear. In this study, we first derived the observed $\Omega$ from 28 FLUXNET sites over North America during 2000-2007, which was then used to evaluate $\Omega$ in six large-scale model-based datasets. Our results confirm the importance of incorporating canopy height in the formulation of aerodynamic conductance in the case of forests. Furthermore, leaf area index (LAI) is central to the prediction of $\Omega$ and can be quantitatively linked to the partitioning between transpiration and soil evaporation $\left(\mathrm{R}^{2}=\right.$ 0.43). The substantial differences between observed and model-based $\Omega$ in forests (range: $0.2 \sim 0.9$ ) This article is protected by copyright. All rights reserved. 
are highly related to the way these models estimated PET and the way they represented the responses of $\Omega$ to the environmental drivers, especially wind speed and LAI. This is the first assessment of $\Omega$ in models based on in-situ observations. Our findings demonstrate that the observed $\Omega$ is useful for evaluating, validating, and optimizing the modelling of AET and thus of water and energy balances.

\section{Introduction}

Terrestrial evapotranspiration (ET) is the sum of soil and open water evaporation, plant transpiration, and rainfall interception by the canopy. ET is a critical process linking water resources (Oki \& Kanae, 2006; Gedney et al., 2006) and carbon-climate feedbacks (Shukla \& Mintz,1982; Field et al., 1995; Ponce-Campos et al., 2013; Zeng et al., 2018a), and understanding the ET process has important implications for agricultural management (Allen et al., 1998; Fisher et al., 2017; D’Odorico et al., 2018). When surface water supply is unlimited, ET reaches an upper limit bounded by atmospheric evaporative demand, also known as potential evapotranspiration (PET). The actual ET (AET) over land will fall short of PET due to surface biophysical limitations. The effect of these limitations can be captured in a single empirical stress factor $(\Omega)$, which can be expressed as the ratio of AET to PET. Using $\Omega$ to constrain PET has been widely used as a simple but effective approach for estimating AET in hydrological models (Schaake et al., 1996; Caylor et al., 2005; Fisher et al., 2008; Miralles et al., 2011; van Beek et al., 2011) and earth system models (Dufresne et al., 2013; Kay et al., 2015). In agriculture, this approach is often used to quantify water availability (Ritchie, 1998), to estimate irrigation requirements (Allen et al., 1998), and to monitor crop water stress (Jackson et al., 1981; Anderson et al., 2007, 2011).

While $\Omega$ is often related to water availability, it is determined to a greater extent by the relative importance of biophysical control (surface conductance) versus aerodynamic control (aerodynamic conductance) of AET (Jarvis \& McNaughton, 1986). Previous studies have revealed the roles of water supply (e.g., precipitation, Liu et al., 2017, De Kauwe et al., 2017; soil moisture, Ohta et al., 2008)

This article is protected by copyright. All rights reserved. 
and atmospheric evaporative demand (e.g., radiation, Mallick et al., 2016; vapor pressure deficit, Wullschleger et al., 2000; wind speed, Kim et al., 2014, Barnard \& Bauerle, 2016) in affecting $\Omega$. A variety of phenological vegetation characteristics, such as vegetation cover (Donohue et al., 2010), leaf area index (Launiainen et al., 2016; Liu et al., 2017), and crop growing stages (Allen et al., 1998; Kang et al., 2003), are found to be positively correlated with $\Omega$. While vegetation characteristics related to green leaf coverage have been a focus for understanding the biophysical effects on $\Omega$, not many studies have explored the aerodynamic effect of vegetation vertical structure, such as canopy height (Raupach, 1994; Allen \& Pereira, 2009; Chu et al., 2018), on the variation of $\Omega$. As vegetation grows, a greater roughness due to increased canopy height has the potential to offset the benefits of greater leaf area for $\Omega$. This suggests a need to consider the competition between aerodynamic and biophysical control on AET when explaining the variability of water stress.

Recent progress in the integration of satellite data with eddy covariance measurements has led to a range of process-based or data-driven observational AET datasets (Fisher et al., 2008; Jung et al., 2010; $\mathrm{Mu}$ et al., 2011; Miralles et al., 2011). Nonetheless, huge gaps remain in our ability to represent AET in the existing diagnostic datasets, land surface models, and reanalyses (Mueller et al., 2013; Greve et al., 2014) and to understand the variability of AET (Wang \& Dickinson, 2012; Katul et al., 2012; Zhang et al., 2015). Uncertainty in AET estimates is caused by at least (1) the different PET approaches (Sheffield et al., 2012; Peng et al., 2018), (2) the complexity of the parameterization of the biophysical limitations (Chen et al., 1996), and (3) the partitioning of AET between soil evaporation and transpiration (Lawrence et al., 2007). Given the wide spectrum of parameterization schemes and input sources, it is challenging to find a common variable (e.g., canopy conductance) to evaluate the representation of the biophysical processes in different models. In practice, $\Omega$ can be easily calculated from model outputs and is a useful metric for evaluating the biophysical processes and explaining the error in ET model structure (Polhamus et al., 2013; De Kauwe et al., 2017). However, the mean and temporal variability of $\Omega$ derived from large-scale model-based datasets generally have not been evaluated against observations. A mechanistic understanding of the errors of $\Omega$ derived from the This article is protected by copyright. All rights reserved. 
models should help improve the modeling of AET dynamics and reduce the uncertainty in the predictions of water, energy, and carbon balances.

The primary goals of this study are (i) to examine the seasonal variations of $\Omega$ derived from eddy covariance flux measurements across a broad range of climates and biomes in North America; (ii) to understand the climate and vegetation controls on seasonal variability of $\Omega$; and (iii) to evaluate the accuracy of $\Omega$ derived from the large-scale diagnostic observational datasets, land surface models, reanalysis products, and terrestrial biosphere models at the eddy covariance sites.

\section{Materials and methods}

\section{Overview of the AET/PET ratio}

PET and AET can be calculated from the Penman (Penman, 1948) and the Penman-Monteith (P-M, Monteith, 1965) equation as

$$
\begin{aligned}
& P E T=\frac{\Delta\left(R_{n}-G\right)+\rho_{a} C_{p} D g_{a}}{\lambda(\Delta+\gamma)} \\
& A E T=\frac{\Delta\left(R_{n}-G\right)+\rho_{a} C_{p} D g_{a}}{\lambda\left(\Delta+\gamma\left(1+\frac{g_{a}}{g_{s}}\right)\right)}
\end{aligned}
$$

where PET and AET are expressed as water mass fluxes $\left(\mathrm{kg} \mathrm{m}^{-2} \mathrm{~s}^{-1}\right), R_{n}$ is the surface net radiation $\left(\mathrm{W} \mathrm{m}{ }^{-2}\right), G$ is the surface ground heat flux $\left(\mathrm{W} \mathrm{m}^{-2}\right), \Delta$ is the slope of the saturation vapor pressure curve at the temperature of interest $\left(\mathrm{Pa} \mathrm{K}^{-1}\right), \gamma$ is the psychrometric constant $\left(\mathrm{Pa} \mathrm{K}^{-1}\right), \lambda$ is the latent heat of vaporization $\left(\mathrm{J} \mathrm{kg}^{-1}\right), \rho_{a}$ is the air density $\left(\mathrm{kg} \mathrm{m}^{-3}\right), C_{p}$ is the specific heat of air $\left(\mathrm{J} \mathrm{kg}^{-1} \mathrm{~K}^{-1}\right)$, and $D$ is the vapor pressure deficit (VPD, Pa). $g_{a}$ is the aerodynamic conductance $\left(\mathrm{m} \mathrm{s}^{-1}\right)$ and quantifies how easily fluxes are transported from the canopy to the atmosphere. $g_{s}$ is the surface conductance $\left(\mathrm{m} \mathrm{s}^{-1}\right)$ which quantifies how easily water is transported from roots to the canopy surface,

This article is protected by copyright. All rights reserved. 
and it consists of canopy conductance, soil conductance, and conductance from the canopy interception.

The ratio of AET to PET, given by combining Eq.1 and Eq.2, is

$$
\Omega=\frac{A E T}{P E T}=\frac{1+\frac{\Delta}{\gamma}}{1+\frac{\Delta}{\gamma}+\frac{g_{a}}{g_{s}}}
$$

The inverse of the AET/PET ratio introduces a linear relation between this quantity and the ratio of $g_{a} / g_{s}$, written as

$$
\frac{P E T}{A E T}=1+\frac{\gamma}{\Delta+\gamma} \cdot \frac{g_{a}}{g_{s}}
$$

$\Omega$ is a function of $g_{s}$ and $g_{a}$ (Eq.3), which is also referred to as the "decoupling factor", a measure of the decoupling between atmospheric conditions at the canopy surface and those in the surrounding air, introduced by Jarvis \& McNaughton (1986, appendix A27). Conversely, $(1-\Omega)$ describes the coupling between canopy and the ambient atmosphere and represents the sensitivity of the fractional change in AET to the fractional change in $g_{s}$ (Jarvis \& McNaughton, 1986, appendix A29):

$$
1-\Omega=\frac{\frac{\partial A E T}{A E T}}{\frac{\partial g_{s}}{g_{s}}}
$$

where a $1 \%$ change in $g_{s}$ will cause a corresponding $(1-\Omega) \%$ change in AET.

In summary, $\Omega$ is a useful metric that illustrates the partitioning between atmospheric demand control and surface biophysical control over AET. $\Omega$ is a nonlinear positive function of the $g_{s} / g_{a}$ ratio, ranging from 0 to 1 (Eq.3, Fig.3b). When $g_{s} \ll g_{a}\left(g_{a} / g_{s} \rightarrow \infty\right), \Omega$ goes to 0 , meaning that the canopy is fully coupled with the surrounding atmospheric conditions. As $(1-\Omega)$ approaches $1, \Omega$

This article is protected by copyright. All rights reserved. 
increases rapidly with $g_{s} / g_{a}$, and the sensitivity of changes in AET to the changes in $g_{s}$ reaches its maximum (Eq.5). Thus, AET is supply-limited under water-stressed conditions and the biophysical control over AET becomes dominant. When $g_{s} \gg g_{a}\left(g_{a} / g_{s} \rightarrow 0\right), \Omega$ approaches 1 , meaning that the canopy atmospheric conditions are fully decoupled from those of the free airstream. As $(1-\Omega)$ is very small, the relative change in AET is almost independent of the relative change in $g_{s}$. Thus, AET is demand-limited and totally regulated by the available energy and aerodynamic control.

\section{In-situ data}

We utilized the data from a North American subset of the La Thuile eddy flux dataset (http://fluxnet.fluxdata.org/data/la-thuile-dataset/) developed by the global network of micrometeorological tower sites, FLUXNET. The FLUXNET dataset is a harmonized, standardized, and gap-filled synthesis database at 30-minute resolution. We selected a broad range of sites by applying the following quality-control flags: (1) site years were restricted to the period of 2000-2007 to ensure long enough records; (2) sites were restricted to the North America area within $25^{\circ}-50^{\circ} \mathrm{N}$ and $50^{\circ}-120^{\circ} \mathrm{W}$ to include locations across different climates; (3) time steps were discarded if there were no data on latent heat $(L E)$, sensible heat $(H)$, air temperature $\left(T_{a}\right)$, net radiation $\left(R_{n}\right)$, global radiation $(R g)$, vapor pressure deficit (VPD), wind speed, or frictional velocity $\left(u_{*}\right)$; (4) nighttime records were excluded when $R g<10 \mathrm{~W} \mathrm{~m}^{-2}$; (5) sites with less than 2 years of temporal coverage were excluded. We finally selected 28 sites spanning a range of vegetation and climate types that satisfy the above criteria (Fig. 1b).

Across these 28 sites, there are seven vegetation types based on the International GeosphereBiosphere Program (IGBP) land cover type classification: evergreen needleleaf forest (ENF), deciduous broadleaf forest (DBF), mixed forest (MF), cropland (CRO), grassland (GRA), woody savanna (WSA), and closed shrubland (CSH). There are eight climate types based on the Köppen-

This article is protected by copyright. All rights reserved. 
Geiger (K-G) climate classification (Kottek, 2006): Hot summer Continental (Dfa), Warm Summer Continental (Dfb), Subarctic Continental (Dfc), Cold Semi-arid (Bsk), Hot summer Mediterranean (Csa), Warm summer Mediterranean (Csb), Humid Subtropical (Cfa), and Oceanic Warm Temperate $(\mathrm{Cfb})$. Detailed site information is listed in Table 1.

The leaf area index (LAI) for each site was obtained from the MOD15A2H version 6 L4 8-day composite LAI product at 500-meter pixel resolution (Myneni \& Park, 2015; ORNL DAAC, 2018). When obtaining the monthly LAI, we first selected the pixel where the site is located. If this pixel does not pass the quality control, we used the average of the 8 neighboring pixels (range of $1.5 \mathrm{~km}$ ) to approximate the site value. To minimize errors associated with clouds, we used the maximum 8-day value during a month to represent the monthly LAI.

Table 1. List of the flux tower sites used in this study with their FLUXNET Identifier (ID), Latitude (LAT), Longitude (LON), IGBP land cover (IGBP), Köppen-Geiger climate (K-G), period of record (PERIOD), and principle investigator (PI).

\begin{tabular}{ccccccc}
\hline & ID & LAT, LON & IGBP & K-G & PERIOD & PI \\
\hline 1 & CA-Ca1 & $49.87,-125.33$ & ENF & Cfb & $2000-2005$ & T. Andrew Black \\
2 & CA-Ca3 & $49.53,-124.9$ & ENF & Cfb & $2001-2005$ & T. Andrew Black \\
3 & CA-Qcu & $49.27,-74.04$ & ENF & Dfc & $2001-2006$ & Hank A. Margolis \\
4 & CA-Qfo & $49.69,-74.34$ & ENF & Dfc & $2003-2006$ & Hank A. Margolis \\
5 & CA-TP4 & $42.71,-80.36$ & ENF & Dfb & $2003-2005$ & M. Altaf Arain \\
6 & US-ARM & $36.61,-97.49$ & CRO & Cfa & $2003-2006$ & Sebastien Biraud \\
7 & US-Aud & $31.59,-110.51$ & GRA & Bsk & $2002-2006$ & Tilden Meyers \\
8 & US-Blo & $38.9,-120.63$ & ENF & Csa & $2000-2006$ & Allen Goldstein \\
9 & US-Bo1 & $40.01,-88.29$ & CRO & Dfa & $2000-2007$ & Tilden Meyers \\
10 & US-FPe & $48.31,-105.1$ & GRA & Bsk & $2000-2006$ & Tilden Meyers
\end{tabular}

This article is protected by copyright. All rights reserved. 


\begin{tabular}{rcccccc}
11 & US-Goo & $34.25,-89.87$ & GRA & Cfa & $2002-2006$ & Tilden Meyers \\
12 & US-Me2 & $44.45,-121.56$ & ENF & Csb & $2003-2005$ & Bev Law \\
13 & US-MMS & $39.32,-86.41$ & DBF & Cfa & $2000-2005$ & Kim Novick \\
14 & US-MOz & $38.74,-92.2$ & DBF & Cfa & $2004-2006$ & Jeffrey Wood \\
15 & US-Ne1 & $41.17,-96.48$ & CRO & Dfa & $2001-2005$ & Andy Suyker \\
16 & US-Ne2 & $41.16,-96.47$ & CRO & Dfa & $2001-2005$ & Andy Suyker \\
17 & US-Ne3 & $41.18,-96.44$ & CRO & Dfa & $2001-2005$ & Andy Suyker \\
18 & US-NR1 & $40.03,-105.55$ & ENF & Dfc & $2000-2003$ & Peter Blanken \\
19 & US-SO3 & $33.38,-116.62$ & CSH & Csa & $2000-2006$ & Walt Oechel \\
20 & US-SP2 & $29.76,-82.24$ & ENF & Cfa & $2000-2004$ & Tim Martin \\
21 & US-SP3 & $29.75,-82.16$ & ENF & Cfa & $2000-2004$ & Tim Martin \\
22 & US-SRM & $31.82,-110.87$ & WSA & Bsk & $2004-2006$ & Russell Scott \\
23 & US-Syv & $46.24,-89.35$ & MF & Dfb & $2002-2006$ & Ankur Desai \\
24 & US-Ton & $38.43,-120.97$ & WSA & Csa & $2001-2006$ & Dennis Baldocchi \\
25 & US-Var & $38.41,-120.95$ & GRA & Csa & $2001-2006$ & Dennis Baldocchi \\
26 & US-WCr & $45.81,-90.08$ & DBF & Dfb & $2000-2006$ & Ankur Desai \\
27 & US-Wkg & $31.74,-109.94$ & GRA & Bsk & $2004-2006$ & Russell Scott \\
\hline 2 & US-Wrc & $45.82,-121.95$ & ENF & Csb & $2000-2006$ & Sonia Wharton \\
\hline & & & & & & \\
\hline
\end{tabular}

\section{Estimating $\Omega$ from observations}

To estimate $\Omega$, we used observed AET and calculated PET from meteorological forcing based on Eq.1. Although $\Omega$ can be derived from $g_{a}$ and $g_{s}$ using Eq.3, directly calculating $\Omega$ with PET using Eq.1 is preferred because only $g_{a}$ estimation is needed, which excludes additional uncertainties associated with inverted $g_{s} \cdot g_{a}$ can be defined as the inverse of aerodynamic resistance for momentum and excess resistance in series (Verma, 1989):

$$
\frac{1}{g_{a}}=r_{a h}=\frac{u}{u_{*}^{2}}+\frac{1}{k u_{*}}\left(\ln \left(\frac{z_{0 m}}{z_{0 h}}\right)+\Psi_{m}\left(\frac{z-d_{0}}{L}\right)-\Psi_{h}\left(\frac{z-d_{0}}{L}\right)+\Psi_{h}\left(\frac{z_{0 h}}{L}\right)-\Psi_{m}\left(\frac{z_{0 m}}{L}\right)\right)
$$

This article is protected by copyright. All rights reserved. 
where $\Psi_{\mathrm{m}}$ and $\Psi_{\mathrm{h}}$ are stability functions for momentum and heat, $z$ is the measurement reference height $(\mathrm{m}), u$ is the wind speed at reference height $\left(\mathrm{m} \mathrm{s}^{-1}\right), u_{*}$ is the frictional velocity $\left(\mathrm{m} \mathrm{s}^{-1}\right), k$ is the von Karman constant, $d_{0}$ is the zero-plane displacement height $(\mathrm{m}), z_{0 m}$ and $z_{0 h}$ are the roughness lengths for momentum and heat (m), and $L$ is the Obukhov length (m). $z_{0 m}$ and $d_{0}$ are assumed to be a function of canopy height (h), as $z_{0 m}=\mathrm{h} / 7.6$ and $d_{0}=2 \mathrm{~h} / 3$ (Brutsaert, 1982).

The term $\ln \left(z_{0 m} / z_{0 h}\right)$, typically defined as $k B^{-1}$, quantifies the relationship between roughness length for heat and momentum. The parameterization of $k B^{-1}$ is important for the transport of heat and water vapor and associated land surface processes (Rigden et al., 2018). We selected the following power function of the roughness Reynolds number $\left(R e_{*}=u_{*} z_{0 m} / v\right)$ implemented in the Noah model (Zilitinkevich, 1995; Chen et al., 1997), where $v$ is kinematic viscosity for air (= $\left.1.46 \times 10^{-5} \mathrm{~m}^{2} \mathrm{~s}^{-1}\right)$

$$
k B^{-1}=k C_{z i l} \sqrt{u_{*} z_{0 m} / v}
$$

$C_{z i l}$ is a critical parameter determining $k B^{-1}$ and varies with land cover type (Chen \& Zhang, 2009). We followed the work of Rigden et al. (2018) in estimating the coefficient $C_{2}\left(=k C_{z i l}\right.$, where $k$ is the von Karman constant $)$ for each land cover. We adopted smaller $C_{z i l}$ values $\left(C_{2}=0.005, C_{z i l}=0.0125\right)$ at forests sites including ENF, DBF, and MF, and larger $C_{z i l}$ values at $\mathrm{CRO}\left(C_{2}=0.06, C_{z i l}=0.15\right)$, GRA $\left(C_{2}=0.1, C_{z i l}=0.25\right)$, and CSH and WSA $\left(C_{2}=0.05, C_{z i l}=0.125\right)$ sites.

The Obukhov length $L$ is defined as

$$
L=\frac{-u_{*}^{3} \rho_{a} T_{a} \cdot(1+0.61 q) \cdot C_{p}}{k g H}
$$

where $T_{a}$ is air temperature (Kelvin), $q$ is the specific humidity $\left(\mathrm{kg} \mathrm{kg}^{-1}\right), g$ is the gravitational acceleration $\left(9.81 \mathrm{~m} \mathrm{~s}^{-2}\right)$, and $H$ is the sensible heat flux $\left(\mathrm{W} \mathrm{m}^{-2}\right)$. Following Sun \& Mahrt (1995), the

This article is protected by copyright. All rights reserved. 
stability functions for momentum and heat are empirical functions of the stability parameter $\zeta=(z-$ $\left.d_{0}\right) / L$ as:

$$
\begin{gathered}
\Psi_{m}=\left\{\begin{array}{cc}
-5 \zeta & 0<\zeta<1 \\
2 \ln \left(\frac{1+x}{2}\right)+\ln \left(\frac{1+x^{2}}{2}\right)-2 \tan ^{-1} x+\frac{\pi}{2} & -5<\zeta<0
\end{array}\right. \\
\Psi_{h}=\left\{\begin{array}{cc}
-5 \zeta & 0<\zeta<1 \\
2 \ln \left(\frac{1+x^{2}}{2}\right) & -5<\zeta<0
\end{array}\right.
\end{gathered}
$$

where $x=(1-16 \zeta)^{1 / 4}$. Since $z_{0 m}$ and $z_{0 h}$ are small compared to $L$, the two terms $\Psi_{\mathrm{m}}\left(\frac{z_{0 m}}{L}\right)$ and $\Psi_{\mathrm{h}}\left(\frac{z_{0 h}}{L}\right)$ in Eq.6 are negligible.

Surface conductance $g_{s}$ is obtained from inverting the Penman-Monteith equation (Eq.2) by employing the computed values of $g_{a}$ as

$$
g_{s}=\frac{1}{r_{s}}=\frac{\gamma g_{a} L E}{\Delta\left(R_{n}-G\right)+\rho_{a} C_{p} D g_{a}-(\Delta+\gamma) L E}
$$

where surface resistance $r_{s}$ is the inverse of $g_{s}$ and $L E$ is the latent heat flux. We also tested the sensitivity of $\Omega$ to other common $g_{a}$ formulations and found that the effects of canopy height and vegetation type on $\Omega$ through $g_{a}$ are important in forests (see Text S1, Fig.S1, and Discussion).

First, the 30-minute FLUXNET data that pass the quality control ("fqcOK" = 1) were selected (Williams et al., 2012). To avoid stable conditions and dewfall conditions during nighttime, we excluded those time steps for which $R g<10 \mathrm{~W} \mathrm{~m}^{-2},\left(R_{n}-G\right) \leq 0 \mathrm{~W} \mathrm{~m}^{-2}, L E \leq 0 \mathrm{~W} \mathrm{~m}^{-2}, H \leq 0 \mathrm{~W} \mathrm{~m}^{-2}$, relative humidity $(R H) \geq 95 \%$, frictional velocity $\left(u_{*}\right) \leq 0.01 \mathrm{~m} \mathrm{~s}^{-1}$, or stability parameter $(\zeta)>1$. Also, when both AET and PET are close to zero during cold seasons, $\Omega$ is approaching 1 and becomes less meaningful in representing water stress and the coupling between canopy and atmosphere.

This article is protected by copyright. All rights reserved. 
Therefore, we restricted our analysis to the non-frozen period with air temperature $>5^{\circ} \mathrm{C}$ (Knauer et al., 2018). Since the Penman method (Eq.1-2) assumes the energy balance to be closed, we discarded time steps in which the error in energy balance closure is above $20 \%$. For time steps in which the energy balance non-closure is within $20 \%$, the energy balance was closed by shifting the measured turbulent fluxes $(H, L E)$ to match available energy $\left(R_{n}-G\right)$ while maintaining the measured Bowen ratio (H/LE) (Twine et al., 2000; Wohlfahrt et al., 2009; Text S2 and Fig.S2). For precipitation (P), we computed the daily cumulative sum for the 30-minute data without discarding any records. For the rest of the meteorological variables, we computed the daily average only for the filtered records and aggregated the daily values to monthly values. For each site year, we derived the annual mean $\Omega$ from the monthly $\Omega$ during the non-frozen season, which is publicly available as supporting data (Data S1) and can be downloaded from the online version of this article.

\section{Model-based datasets}

The magnitude of $\Omega$ depends heavily on the approach used to estimate PET. To ensure consistency in the estimation of $\Omega$ in the large-scale model-based data, we first considered datasets that contain estimates of both AET and PET, including three categories following Mueller et al. (2013): diagnostic datasets based on satellite observations, land surface model (LSM) simulations driven by observationbased forcing, and atmospheric global and regional reanalyses assimilating atmospheric observations. The approach used for AET estimation and the resolution for each dataset are listed in Table 2. There are three satellite products, GLEAM v3.2a (Global Land-surface Evaporation: The Amsterdam Methodology, Miralles et al., 2011, Martens et al., 2017), PT-JPL (Priestley and Taylor Jet Propulsion Laboratory model, Fisher et al., 2008, http://josh.yosh.org/datamodels.htm), and MOD16A2 MODIS/Terra Net Evapotranspiration V006 (hereafter MOD16; Running \& Mu, 2017; ORNL DAAC, 2018). GLEAM is a hydrological model driven by satellite soil moisture, precipitation, and vegetation optical depth. PT-JPL uses the Priestley-Taylor method (Priestley \& Taylor, 1972) with vegetation data from the Advanced Very High Resolution Radiometer (AVHRR) and meteorological

This article is protected by copyright. All rights reserved. 
data from the International Satellite Land Surface Climatology Project Initiative II (ISLSCP-II). MOD16 uses the Penman-Monteith method driven by vegetation data from the MOderate-Resolution Imaging Spectroradiometer (MODIS) and meteorological forcing. We also evaluated the Noah LSM simulation taken from the NLDAS-2 (Phase 2 of the North American Land Data Assimilation System, https://ldas.gsfc.nasa.gov/nldas/NLDAS2model.php) and two reanalyses: CFSR (Climate Forecast System Reanalysis, https://rda.ucar.edu/datasets/ds093.2/) and NARR (North America Regional Reanalysis, https://rda.ucar.edu/datasets/ds608.0/). Both CFSR and NARR use the same four-layer operational Noah land surface model (Ek et al., 2003) with different data assimilation schemes. The main differences among the models are (1) the selection of the Penman-Monteith (P-M) or the Priestley-Taylor (P-T) method for AET simulation and the inclusion or omission of the aerodynamic component for PET, and (2) the complexity incorporated in parameterizing plant water stress or canopy conductance.

Table 2. List of the model-based data with their approach, parameterization scheme for $\Omega$, temporal and spatial resolution, and reference.

\begin{tabular}{|c|c|c|c|c|c|}
\hline & Dataset & Approach & $\mathbf{\Omega}$ parameterization & Resolution & Reference \\
\hline \multirow{3}{*}{ Diagnostic } & $\begin{array}{l}\text { GLEAM } \\
\text { v3.2a }\end{array}$ & Priestley-Taylor & $\begin{array}{l}\text { Root-zone soil moisture, } \\
\text { precipitation, vegetation } \\
\text { optical depth }\end{array}$ & daily/0.25 & $\begin{array}{l}\text { Miralles et } \\
\text { al., } 2011\end{array}$ \\
\hline & PT-JPL & Priestley-Taylor & VPD, vegetation index & monthly $/ 0.5^{\circ}$ & $\begin{array}{l}\text { Fisher et } \\
\text { al., } 2008\end{array}$ \\
\hline & MOD16 & $\begin{array}{l}\text { Priestley-Taylor (plant) } \\
\text { Penman-Monteith (soil) }\end{array}$ & $\begin{array}{l}\text { Conductance based on } \\
\text { meteorology, biomes, } \\
\text { vegetation index }\end{array}$ & 8 -day/500m & $\begin{array}{l}\text { Mu et al., } \\
2011\end{array}$ \\
\hline LSM & Noah & Penman-Monteith & Four-layer soil model, & monthly/0.125 & $\begin{array}{l}\text { Xia et al., } \\
2012\end{array}$ \\
\hline \multirow{2}{*}{ Reanalyses } & CFSR & Penman-Monteith & $\begin{array}{l}\text { Jarvis canopy } \\
\text { conductance }\end{array}$ & monthly $/ 0.5^{\circ}$ & $\begin{array}{c}\text { Saha et al., } \\
2010\end{array}$ \\
\hline & NARR & Penman-Monteith & (Chen et al., 1996) & monthly $/ 32 \mathrm{~km}$ & $\begin{array}{c}\text { Mesinger et } \\
\text { al., } 2006\end{array}$ \\
\hline
\end{tabular}

This article is protected by copyright. All rights reserved. 
We extracted monthly time series of AET and PET for the 2000-2007 period (except for PT-JPL, which is only available for the 1986-1995 period) in the grids collocated with the FLUXNET sites. For GLEAM and MOD16, monthly data were aggregated from the original daily/8-day time step. To compare the observed FLUXNET $\Omega$ with the monthly model outputs, we recalculated the monthly AET and PET from the observations to include both daytime and nighttime data. We set the nighttime AET and PET records $\left(R g<0 \mathrm{~W} \mathrm{~m}{ }^{-2}, R_{n}-G \leq 0 \mathrm{~W} \mathrm{~m}^{-2}\right.$, or $\left.L E \leq 0 \mathrm{~W} \mathrm{~m}^{-2}\right)$ to zero, and linearly interpolated the half-hourly records for averaging.

To further explore the potential uncertainties in the outputs of model/reanalysis, we also utilized the simulated latent heat from 18 terrestrial biosphere models that participated in the North American Carbon Program site-level synthesis (NACP, https://daac.ornl.gov/NACP/). These models are run in single point at the 47 FLUXNET sites driven by the observed environmental forcing (Ricciuto et al., 2013). We calculated $\Omega$ for these models using model-simulated AET and PET calculated from the insitu meteorological forcing at the 16 overlapping sites (see Table S1) and then compared them against $\Omega$ derived from the sites.

\section{Results}

\section{Seasonality of observed $\Omega$}

Fig.1 shows the annual mean non-frozen season $\Omega$ across different vegetation types over the 28 sites. All vegetation types exhibit relatively large AET deviations from PET (small $\Omega$ values with the mean $<0.5)$. On average, CRO sites have the highest $\Omega($ mean $=0.45)$, followed by DBF (mean $=0.32)$ and GRA (mean $=0.29$ ). ENF, MF, WSA, and CSH have lower $\Omega$ with means $=0.23,0.24,0.23$, and 0.17 , respectively. The large ranges in CRO $(0.17 \sim 0.71)$ and GRA $(0.09 \sim 0.58)$ sites arise mainly from site-to-site variability (Fig.S3d, e), while the DBF sites ranging from $0.11 \sim 0.47$ display significant

This article is protected by copyright. All rights reserved. 
inter-annual variability (Fig.S3b). Despite the large number of site years $(\mathrm{N}=48)$, the site-to-site and inter-annual variability of ENF is small (Fig.S3a), with $\Omega$ ranging from $0.14 \sim 0.43$.

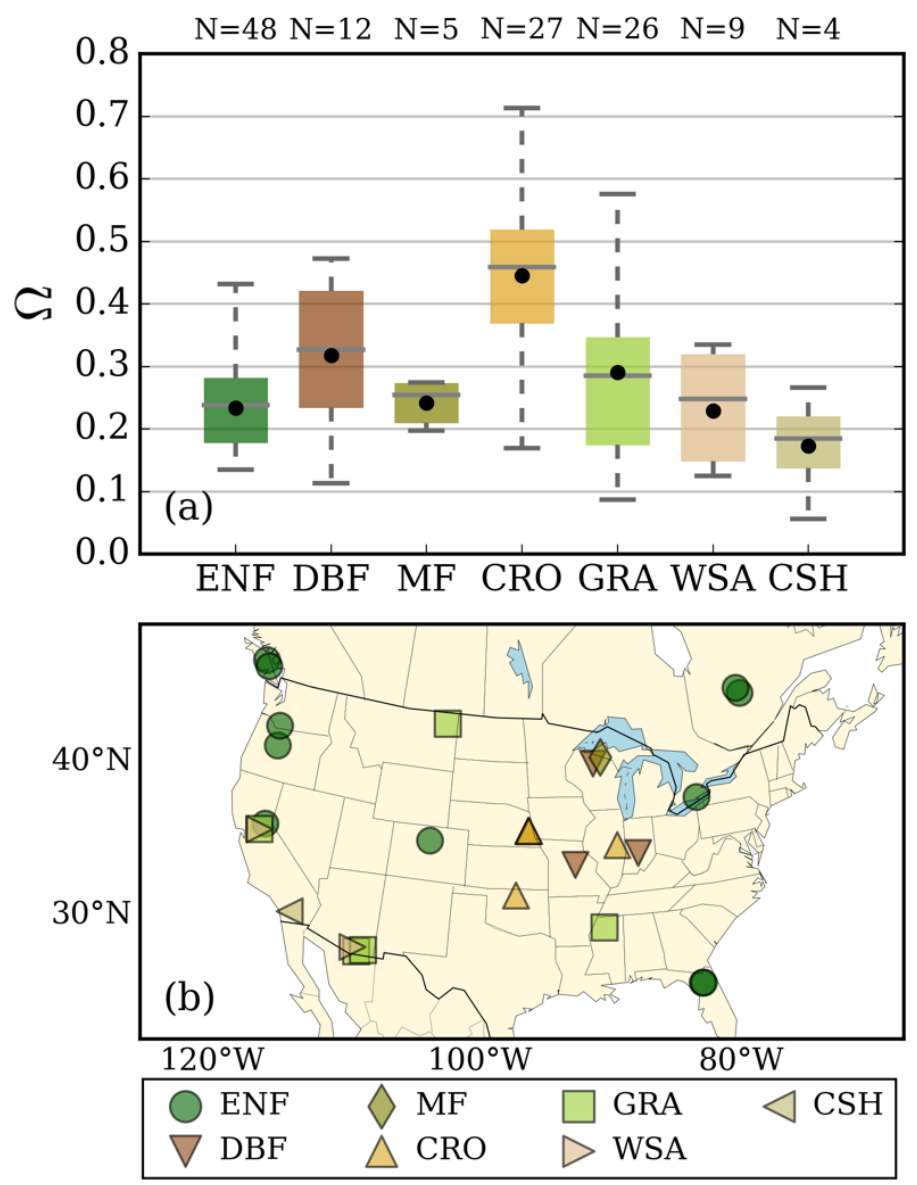

Fig.1 (a) Box plots of annual mean non-frozen season $\Omega$ grouped by the IGBP vegetation types. Each box indicates the interquartile range (top: the third quartile; bottom: the first quartile), with a horizontal grey solid line indicating the median and a black dot referring to the mean. The upper and lower whiskers extend to 1.5 times the interquartile range. The number of site years $(\mathrm{N})$ for each vegetation type is indicated at the top. (b) The spatial distribution of the 28 FLUXNET sites grouped by vegetation types: evergreen needleleaf (ENF), deciduous broadleaf (DBF), mixed forest (MF), cropland (CRO), grassland (GRA), woody savanna (WSA), and closed shrubland (CSH).

We further assessed how $\Omega$ varies with both vegetation and climate types. Fig.2 shows that the seasonal cycle of $\Omega$ varies with the vegetation type for a given climate. For example, under the Humid Subtropical climate (Fig.2g), the DBF sites (i.e., US-MMS, US-MOz) have substantially larger variations in $\Omega$ compared to the ENF sites (i.e., US-SP2, US-SP3). The corn-dominated croplands (CRO) in the Continental climate (Fig.2a) have the highest $\Omega$ among all the vegetation types in July-

This article is protected by copyright. All rights reserved. 
August, because corn farming is water intensive and maintains high rates of AET during the reproductive growth stages. Conversely, $\mathrm{CSH}$ and WSA adopt conservative water use strategies and hence exhibited consistently lower values of $\Omega$, around $0.1 \sim 0.6$ (Fig.2d).

The seasonal cycle of $\Omega$ also varies with different climate regimes and climate seasonalities, which explains much of the site-to-site variability for a given vegetation type in Fig.S3. At the Continental Climate (Df) sites, $\Omega$ is higher in the warm and wet season (Fig.2a-c). $\Omega$ at the Mediterranean (Cs) sites tends to be higher in the rainy season and lower in the warm season due to the lack of soil moisture supply (Fig.2e, f). This is consistent with Ryu et al. (2008) that reported a high $\Omega=0.51$ during the growing season and a low $\Omega=0.27$ averaged across the year for the Mediterranean site, US-Var (see Fig.2e). The seasonal patterns of $\Omega$ at the Cold Semi-arid (Bsk, Fig.2d) sites depend heavily on the annual cycle of precipitation that peaks in July-August, particularly for sites in Arizona (i.e., US-Aud, US-SRM, US-Wkg).
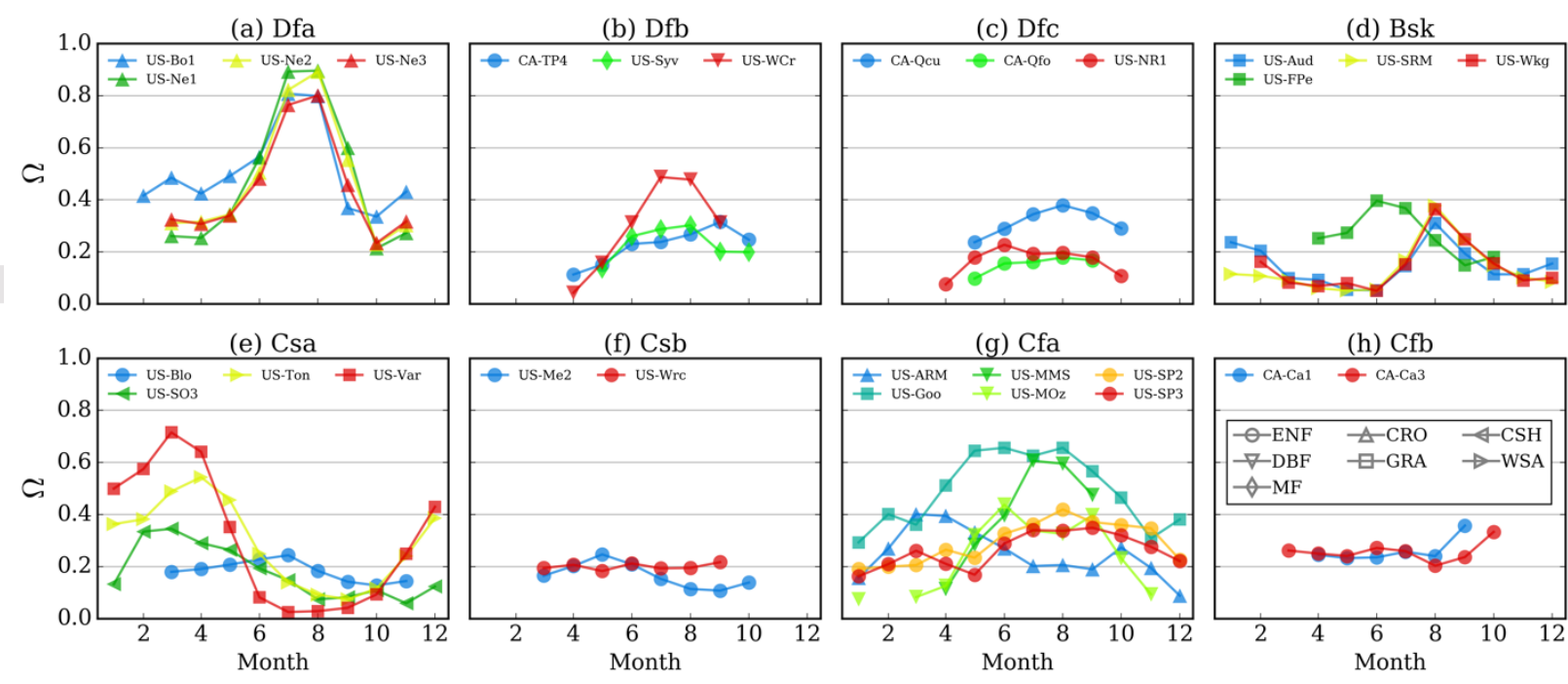

Fig.2 Seasonality of $\Omega$ at the 28 Ameriflux sites grouped by the K-G climate classes. (a) Dfa: Hot summer Continental, (b) Dfb: Warm Summer Continental, (c) Dfc: Subarctic Continental, (d) Bsk: Cold Semi-arid, (e) Csa: Hot summer Mediterranean, (f) Csb: Warm summer Mediterranean, (g) Cfa: Humid Subtropical, (h) Cfb: Oceanic Warm Temperate. The shape of marker indicates different IGBP vegetation type. The colors in each subplot indicate different sites under the same climate.

This article is protected by copyright. All rights reserved. 


\section{Climate and vegetation controls on seasonality of $\Omega$}

Recall that $\Omega$ is determined by the relative importance of $g_{s}$ versus $g_{a}$ (Eq.3-5). The inverse of $\Omega$ $\left(\Omega^{-1}=\right.$ PET/AET) is a linear function of the ratio of $g_{a} / g_{s}$ (Eq.4), which we tested with the monthly FLUXNET data. Fig.3a plots the monthly $\Omega^{-1}$ against monthly $g_{a} / g_{s}$ which yields a reasonably good linear fit $\left(\Omega^{-1}=2.43+0.23 g_{a} / g_{s}, \mathrm{R}^{2}=0.91, \mathrm{p}<0.01\right)$. The fit has a positive bias $(+1.43)$ in the intercept from the theoretical value 1.0 , and the observed sensitivity of $\Omega^{-1}$ to $g_{a} / g_{s}$ is 0.23 (Eq.4). $\Omega$ is a nonlinear positive function of the $g_{s} / g_{a}$ ratio (Eq.3), depicted by Fig.3b. When the influence of $g_{s}$ and $g_{a}$ are comparable $\left(g_{s} / g_{a} \approx 1\right), \Omega$ is centered around 0.7 . Note that the variability of $\Omega$ caused by the differences in the $\Delta / \gamma$ ratio is much smaller than that due to differences in the $g_{s} / g_{a}$ ratio.
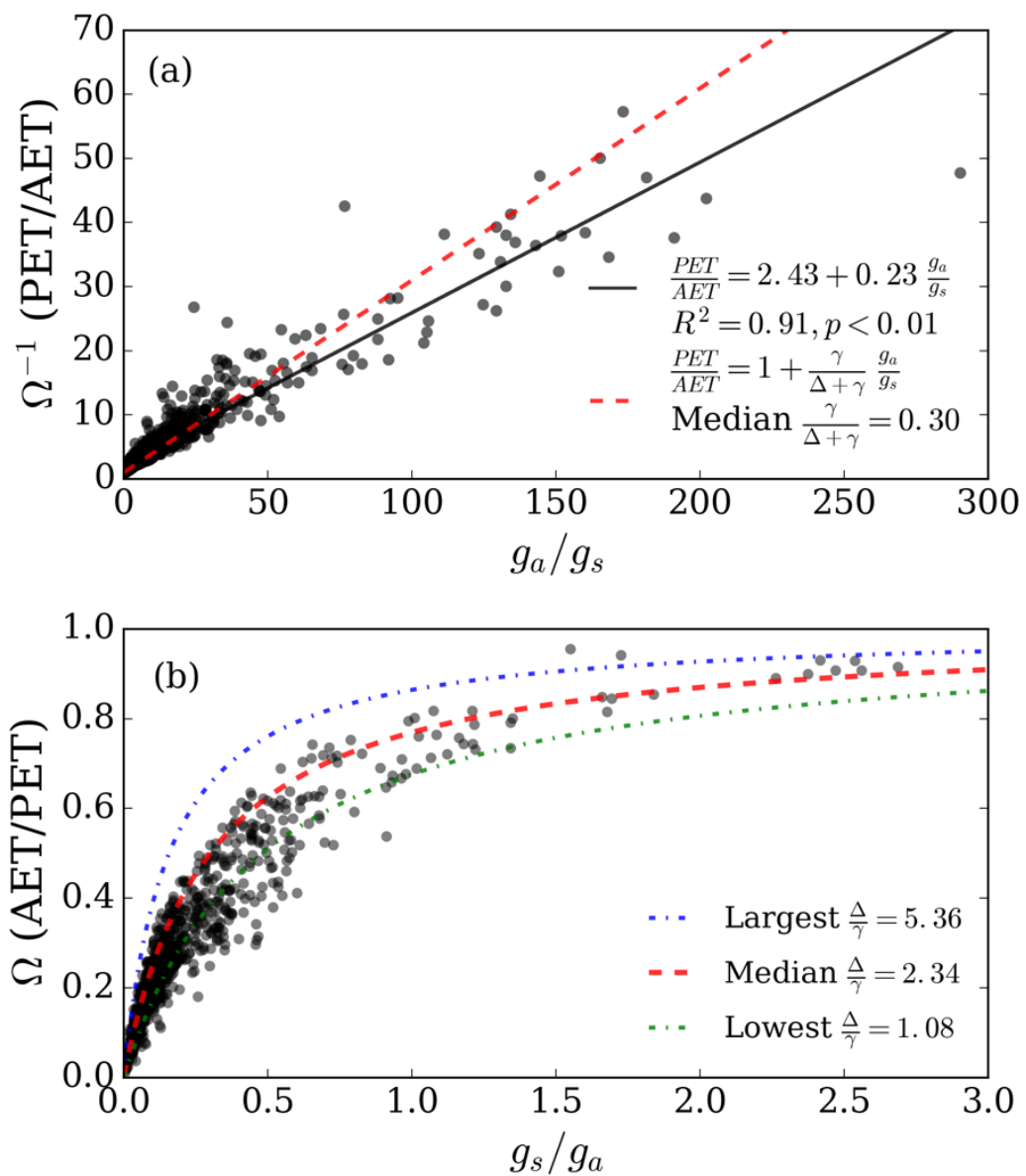

Fig.3 (a) The linear regression relationship between $\Omega^{-1}$ and $g_{a} / g_{s}$ ratio. Each black data point represents an observed monthly $\Omega^{-1}$ under a wide range of $g_{a} / g_{s}$ ratio. The black solid line is the regression fit of all data points. The red dashed line depicts a prediction by the linear equation (Eq.4) with the observed median $\gamma /(\Delta+\gamma)$ ratio. (b) The nonlinear relationship between $\Omega$ and $g_{s} / g_{a}$ ratio. The blue, red, and green dashed lines are the predictions of $\Omega$ using the observed largest, median, and

This article is protected by copyright. All rights reserved. 
lowest monthly $\Delta / \gamma$ ratio to account for the uncertainty of $\Omega$ fitting caused by the differences in the $\Delta / \gamma$ ratio.

We further explored how climate and vegetation factors control the seasonal variations of $\Omega$ through their regulation of $g_{s}$ and $g_{a}$ (Fig.S4 and S5). Fig.4 depicts the relationships between $\Omega$ and climate or vegetation drivers. $\Omega$ increases significantly with monthly total precipitation in ENF (Fig.4a1, $\mathrm{R}^{2}=$ 0.11), CRO (Fig.4a3, R ${ }^{2}=0.23$ ), GRA (Fig.4a4, $\mathrm{R}^{2}=0.33$ ), and WSA and CSH (Fig.4a5, $\mathrm{R}^{2}=0.35$ ). Conversely, rainfall deficit leads to a dry-down in soil moisture, and more negative soil water potential limits plant water uptake and reduces $g_{s}$ to almost zero during the dry season (Fig.S4d, e), and thereby decreases $\Omega$ (Fig.2d, e).

This article is protected by copyright. All rights reserved. 

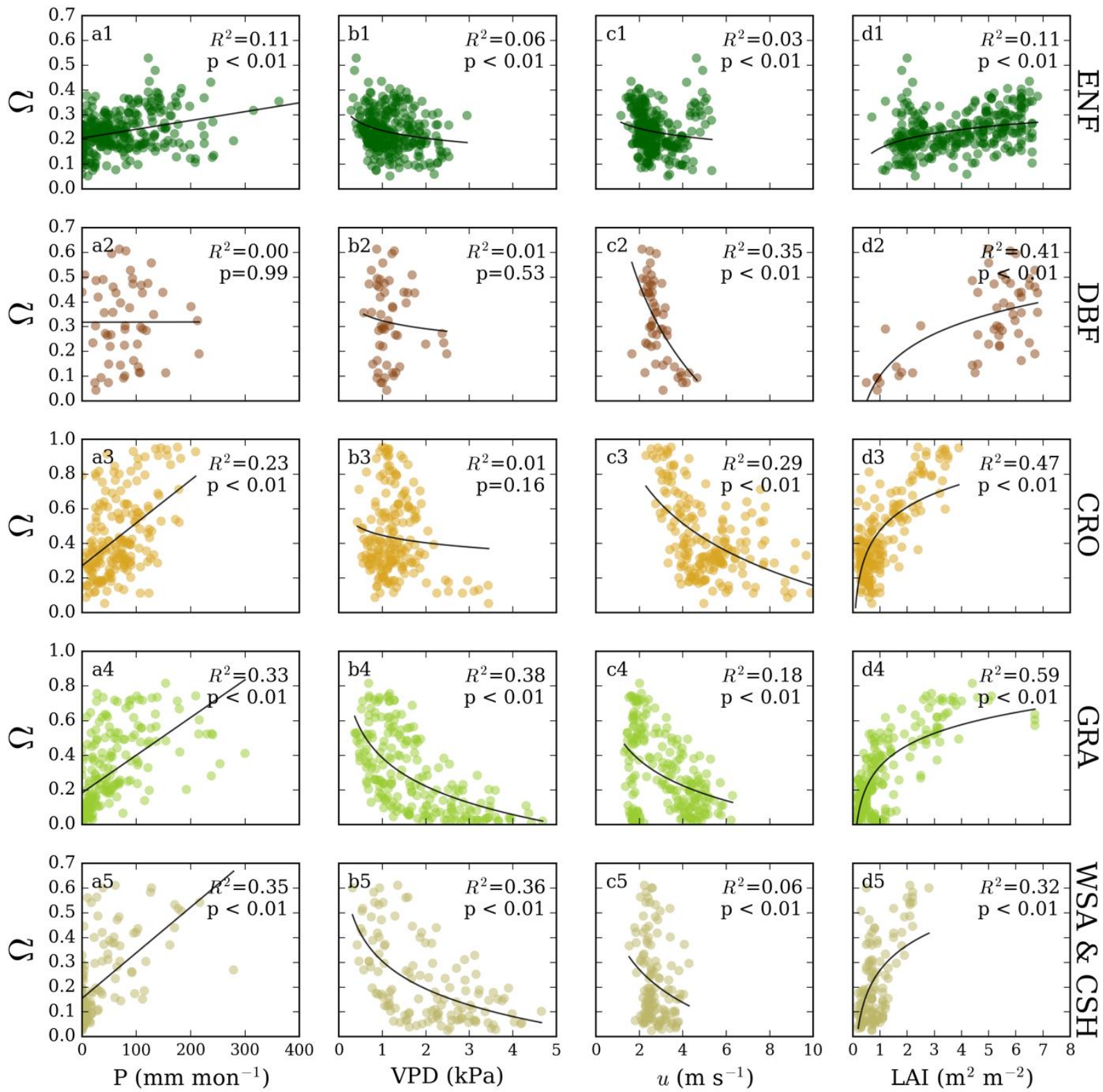

Fig.4 Relationships between monthly $\Omega$ and monthly (a) P: total precipitation, (b) VPD: vapor pressure deficit, (c) $u$ : wind speed, and (d) LAI: leaf area index for different vegetation classes: (1) ENF, (2) DBF, (3) CRO, (4) GRA, (5) WSA and CSH. The grey curve is the line of best fit (using a linear or logarithmic function) with coefficient of determination $\left(R^{2}\right)$ and significance level (p) shown.

$\Omega$ decreases significantly with monthly mean VPD in ENF (Fig.4b1, $\left.\mathrm{R}^{2}=0.06\right)$ and in xeric biomes including GRA (Fig.4b4, $\mathrm{R}^{2}=0.38$ ), and WSA and CSH (Fig.4b5, $\mathrm{R}^{2}=0.36$ ). This negative $\Omega$-VPD relation is associated either with atmospheric drying that forces plants to close stomata in order to avoid excessive water loss (Katul et al., 2009), or with hydraulic limitation on $g_{s}$ (Sperry et al., 2016;

This article is protected by copyright. All rights reserved. 
Anderegg et al., 2016) due to soil moisture deficit, given the strong correlation between VPD and soil moisture that has been found on monthly time scale (Novick et al., 2016a, 2016b). When VPD < $2 \mathrm{kPa}, \Omega$ is not sensitive to VPD in CRO (Fig.4b3, $\mathrm{p}=0.16$ ), as croplands are typically not water stressed, owing to irrigation. $\Omega$ is insensitive to VPD in DBF as well (Fig.4b2, $\mathrm{p}=0.53$ ) where precipitation is not a limiting factor (Fig.4a2, $\mathrm{p}=0.99$ ). Additionally, the relationships of monthly $\Omega$ with $T_{a}$ and $R g$ are similar to those of VPD in GRA, and in WSA and CSH (Fig.S6a4-a5, b4-b5). In mesic DBF sites, as the growing season progresses, solar radiation and temperature increase, and $g_{s}$ becomes higher (Fig.S4b,g), which explains the positive relationship between $\Omega$ and $T_{a}$ (Fig.S6a2, ${ }^{2}$ $=0.32$ ) and $R g$ (Fig.S6b2, $\mathrm{R}^{2}=0.57$ ).

We found that monthly LAI plays a key role in controlling $\Omega$. $\Omega$ increases significantly with LAI in all vegetation types, with $\mathrm{R}^{2}=0.11$ in ENF (Fig. $4 \mathrm{~d} 1$ ), $\mathrm{R}^{2}=0.41$ in DBF (Fig.4d2), $\mathrm{R}^{2}=0.47$ in CRO (Fig.4d3), $\mathrm{R}^{2}=0.59$ in GRA (Fig.4d4), and $\mathrm{R}^{2}=0.32$ in WSA and CSH (Fig.4d5). As LAI increases, $g_{s}$ increases and thus $\Omega$ becomes higher, because $g_{s}$ is proportional to leaf area and the number of stomata (Mu et al., 2011). We further estimated the response of $\Omega$ to LAI ( $\Delta \Omega / \Delta \mathrm{LAI}$, the linear regression slope of monthly $\Omega$ versus monthly LAI) at each site. We are interested in the underlying factors explaining the spatial pattern of $\Delta \Omega / \Delta$ LAI. Fig.S7 shows that $\Delta \Omega / \Delta$ LAI declines from very sensitive $\left(0.4\right.$ per $\left.\mathrm{m}^{2} \mathrm{~m}^{-2}\right)$ to not sensitive $\left(0\right.$ per $\left.\mathrm{m}^{2} \mathrm{~m}^{-2}\right)$ with increasing site-average water supply (P, Fig.S7a, $\mathrm{R}^{2}=0.09$ ) and leaf area (LAI, Fig.S7b, $\mathrm{R}^{2}=0.38$ ). $\Delta \Omega / \Delta \mathrm{LAI}$ is also slightly positively correlated with site-average atmospheric evaporative demand ( $T_{a}$ and VPD, Fig.S7c-d).

We noted that $\Omega$ in ENF is not well explained by environmental variables (Fig.4 Row1, $R^{2}<0.11$ ). In fact, the divergence of $\Omega$ at ENF sites is determined by $g_{a}$ rather than $g_{s}$, as demonstrated by the difference between Fig.S4 and Fig.S5a. $g_{s}$ is similar at all ENF sites, within a range of $0.005 \sim 0.015$ $\mathrm{m} \mathrm{s}^{-1}$ (Fig.S4), while the magnitude of $g_{a}$ for ENF sites varies greatly even for the same climate type, ranging from 0.04 to $0.10 \mathrm{~m} \mathrm{~s}^{-1}$ (Fig.S5a). $g_{a}$ is associated with wind speed and canopy height, as This article is protected by copyright. All rights reserved. 
both enhance $g_{a}$ and thus increase the coupling of atmosphere and canopy (see Materials and Methods). As expected, $\Omega$ decreases significantly with higher monthly mean wind speed in all vegetation types, especially in DBF (Fig.4c2, $\mathrm{R}^{2}=0.35$ ), CRO (Fig.4c3, $\mathrm{R}^{2}=0.29$ ), and GRA (Fig. $4 \mathrm{c} 4, \mathrm{R}^{2}=0.18$ ). To assess the relationship between $\Omega$ and canopy height, we normalized siteaverage $\Omega$ by site-average LAI, which isolates the boosting effect of LAI on $\Omega$. We found that $\Omega$ per unit LAI at ecosystem level follows a power-law relation with canopy height $\left(\right.$ Fig.5, $\left.\mathrm{R}^{2}=0.32\right)$, where $\Omega$ per unit LAI is sensitive to canopy height when canopy height $<20 \mathrm{~m}$.

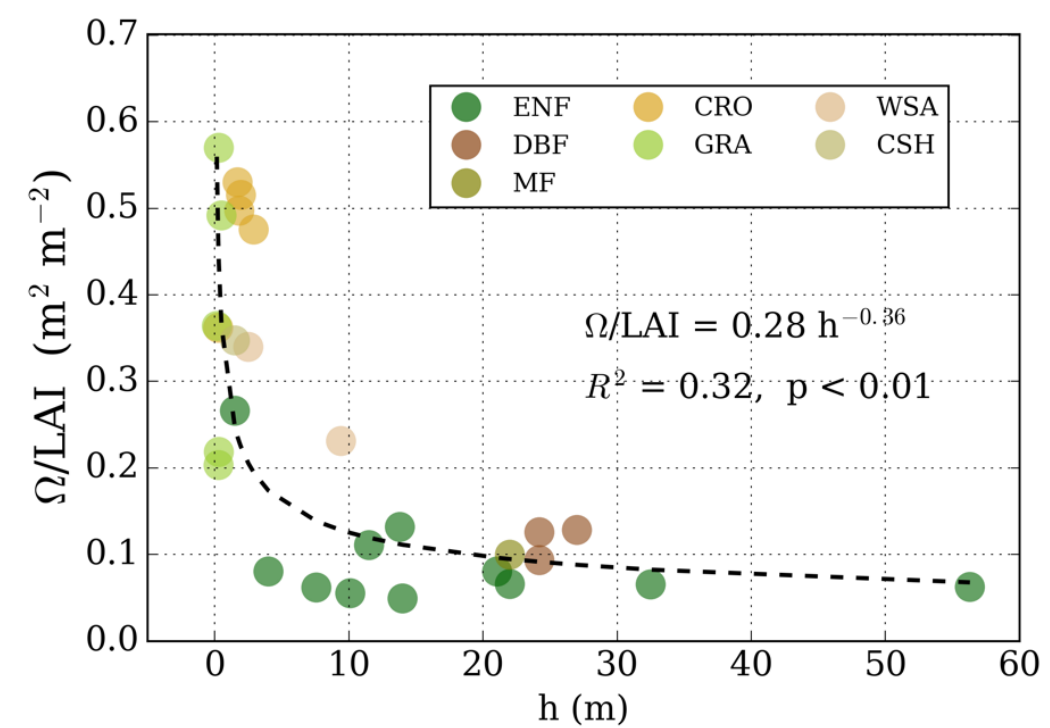

Fig.5 The relationship between site-average $\Omega /$ LAI and canopy height (h) color coded with vegetation type.

\section{Comparison of in-situ observations and model-based datasets}

Based on the interpolated FLUXNET measurements, we calculated the monthly error statistics of the models (Table 3; PT-JPL is excluded due to the different period it covers). We averaged the monthly data during the non-frozen period $\left(T_{a}>5^{\circ} \mathrm{C}\right)$ to obtain the annual mean $\Omega$, PET, and AET, as shown by the colored boxplots in Fig.6. There are large differences among the model-based datasets, with mean $\Omega$ ranging from 0.1 to 0.9 (Fig.6a). $\Omega$ derived from Noah agrees with that from FLUXNET very well, with the smallest Root-Mean-Squared-Errors (RMSE) in ENF, DBF, and CRO sites, as well as

This article is protected by copyright. All rights reserved. 
the highest correlations in CRO, GRA, WSA and CSH sites (bias $=-0.12 \sim-0.04, \mathrm{R}=0.34 \sim 0.93$, Table 3). Both MOD16 and NARR are consistent with FLUXNET in short-grass vegetation (CRO, GRA, WSA, and CSH) with small biases and high correlations (bias $=-0.16 \sim 0.04, \mathrm{R}=0.53 \sim 0.91$, Table 3). GLEAM and PT-JPL have much larger values of $\Omega$ (mean $=0.53 \sim 0.89)$ compared to FLUXNET $($ mean $=0.22 \sim 0.49)$ and the other datasets. Conversely, CFSR has very low magnitudes (mean $=0.13 \sim 0.23)$ and small variability (range $=0.21 \sim 0.33)$ in $\Omega$. The divergence in $\Omega$ magnitudes in different models tends to follow the patterns of PET magnitudes, as displayed in Fig.6b. Specifically, GLEAM and PT-JPL, which are based on the P-T approach, have lower PET (3 $\left.\sim 5 \mathrm{~mm} \mathrm{~d}^{-1}\right)$ than either FLUXNET or the other models that use the P-M approach $\left(5 \sim 15 \mathrm{~mm} \mathrm{~d}^{-1}\right)$.

In general, PET estimates remain relatively consistent within each model regardless of vegetation type. The patterns among vegetation types in Fig.6a tend to follow that of AET in Fig.6c. For example, in FLUXNET, both AET and $\Omega$ are higher in croplands and lower in semi-arid ecosystems (GRA, WSA, CSH). Noah has AET patterns (Fig.6c) similar to those in FLUXNET (Fig.6a) across vegetation types. GLEAM, MOD16, and Noah capture the mean and spread of AET in short-grass vegetation (CRO, GRA, WSA, CSH), while PT-JPL, CFSR, and NARR yield higher mean and larger spread compared to the FLUXNET values. For forests (ENF and DBF), all models except for Noah predict much higher AET rates and hence higher $\Omega$ values. However, PET estimates from some models (MOD16, CFSR, NARR) are often lower in forests than in short-grass vegetation (Fig.6b). The contrasting behaviors of AET and PET in forests result in even larger $\Omega$ values in these models (Fig.6a).

This article is protected by copyright. All rights reserved. 

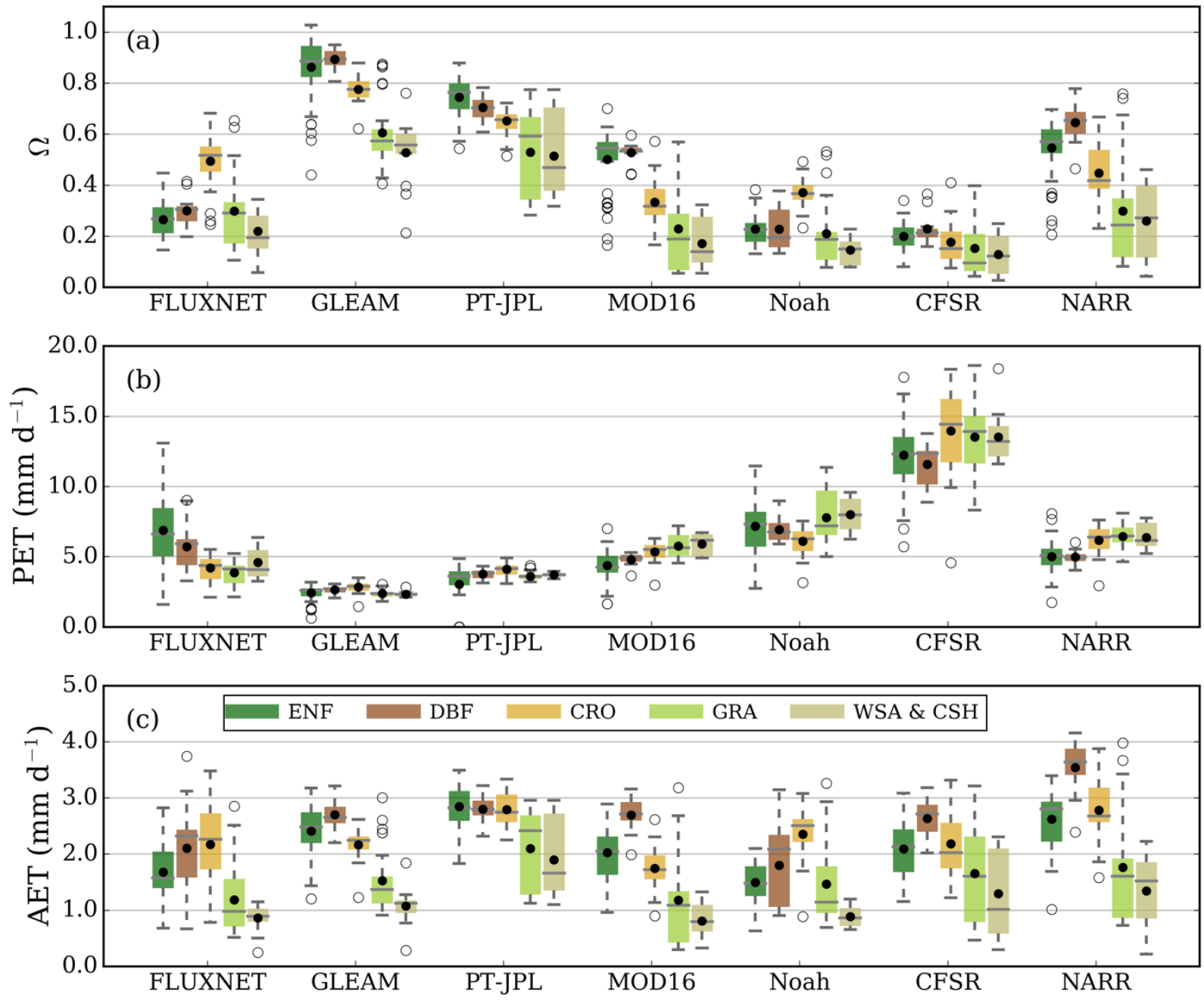

Fig.6 Annual mean (a) $\Omega$, (b) PET, and (c) AET from the FLUXNET data and the model-based datasets. For each data source, the annual mean $\Omega$ are shown by box plots as in Fig.1a for different vegetation classes: ENF, DBF, CRO, GRA, and WSA and CSH. Black circles outside of the whiskers indicate the outliers.

This article is protected by copyright. All rights reserved. 
Table 3. Statistics of comparison between the FLUXNET observations and the model-based datasets in different vegetation types, including bias, Root-Mean-Squared-Error (RMSE), and correlation (R). Statistics with asterisks indicate the correlations are not significant.

\begin{tabular}{|c|c|c|c|c|c|c|c|c|c|c|c|c|c|c|c|}
\hline & & GLEAN & & & MOD16 & & & Noah & & & CFSR & & & NARR & \\
\hline Туре & Bias & RMSE & $\mathbf{R}$ & Bias & RMSE & $\mathbf{R}$ & Bias & RMSE & $\mathbf{R}$ & Bias & RMSE & $\mathbf{R}$ & Bias & RMSE & $\mathbf{R}$ \\
\hline ENF & 0.59 & 0.62 & 0.30 & 0.24 & 0.27 & 0.49 & -0.04 & 0.11 & 0.42 & -0.06 & 0.15 & 0.27 & 0.28 & 0.32 & 0.41 \\
\hline DBF & 0.59 & 0.62 & $-0.02 *$ & 0.22 & 0.26 & 0.65 & -0.06 & 0.18 & 0.34 & -0.06 & 0.21 & $0.00 *$ & 0.35 & 0.37 & 0.67 \\
\hline CRO & 0.28 & 0.36 & $0.13 *$ & -0.16 & 0.23 & 0.68 & -0.12 & 0.19 & 0.76 & -0.33 & 0.39 & 0.23 & -0.05 & 0.20 & 0.53 \\
\hline GRA & 0.31 & 0.35 & 0.82 & -0.06 & 0.14 & 0.83 & -0.09 & 0.15 & 0.89 & -0.14 & 0.20 & 0.79 & 0.00 & 0.11 & 0.89 \\
\hline $\begin{array}{c}\text { WSA\& } \\
\text { CSH }\end{array}$ & 0.31 & 0.37 & 0.78 & -0.05 & 0.11 & 0.81 & -0.08 & 0.10 & 0.93 & -0.09 & 0.13 & 0.85 & 0.04 & 0.12 & \\
\hline
\end{tabular}
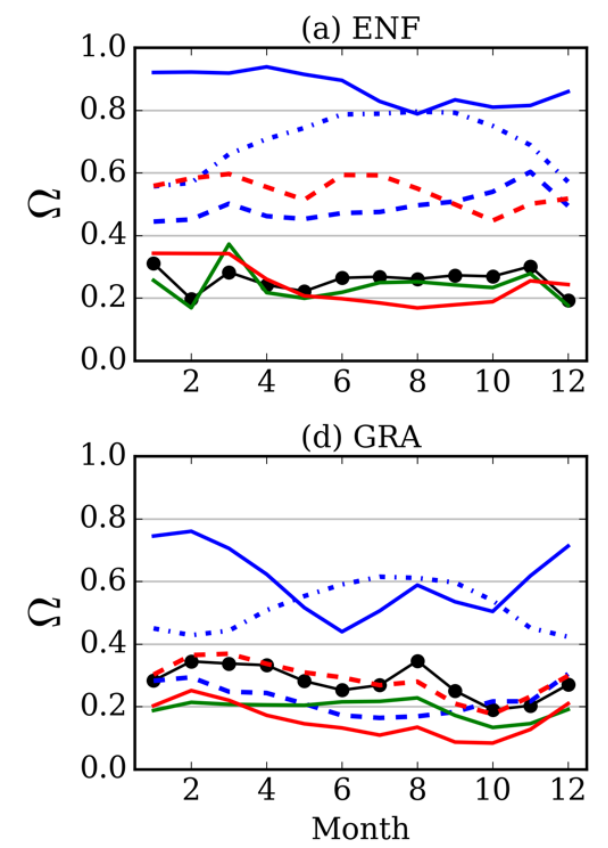

(b) $\mathrm{DBF}$

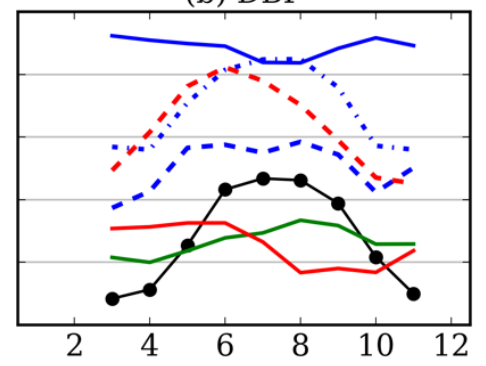

(e) WSA \& CSH

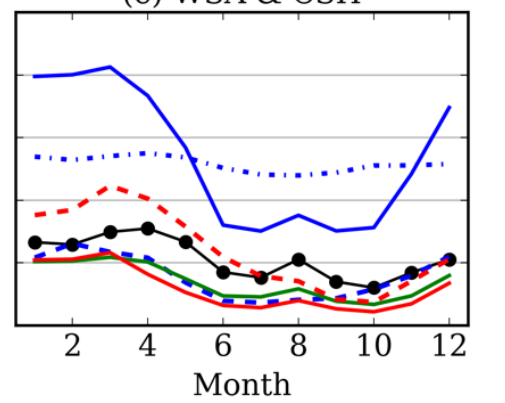

(c) $\mathrm{CRO}$
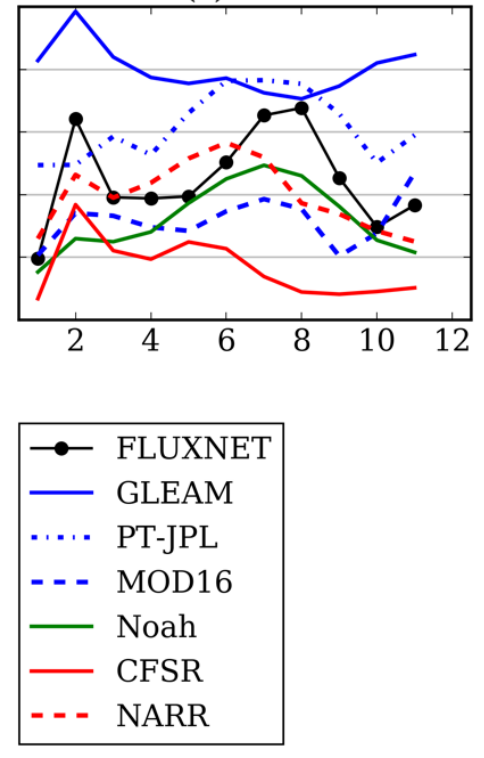

Fig.7 Seasonality of $\Omega$ in the FLUXNET data and the model-based datasets for different vegetation classes.

This article is protected by copyright. All rights reserved. 
The magnitudes and seasonal cycles of $\Omega$ in Noah are highly consistent with that in FLUXNET (Fig.7). MOD16 and NARR also capture the seasonal variability of $\Omega$, shown by their high correlations with $\Omega$ from FLUXNET for all vegetation types (Table 3), but they have positive biases in ENF and DBF sites and negative biases in CRO sites (shown by blue and red dashed lines in Fig.7). The seasonal cycles of $\Omega$ in GLEAM are very different from that in FLUXNET and the other models, with smallest seasonal variability in forests. The large values during the cold season in particular contribute to the large annual mean $\Omega$ in GLEAM (Fig.6a). Overall, we found that the model-based datasets capture the observed seasonality better in semi-arid grasslands and shrublands (GRA, WSA, $\mathrm{CSH}, \mathrm{R}=0.78 \sim 0.93)$ than in forests and croplands (ENF, DBF, CRO, $\mathrm{R}=-0.02 \sim 0.67)$.

To further explore the processes behind the divergence of model-based $\Omega$ shown in Fig.6 and 7, we examined the relationships between model-based $\Omega$ and climate or vegetation drivers, and compared these with the same relationships from the FLUXNET observations. We performed linear regressions of the $\Omega$ derived from the models as well as from the interpolated FLUXNET data versus the variables in Fig.4, with slopes displayed in Fig.8. Similar to the findings in the observations, larger $\Omega$ is associated with higher precipitation especially in semi-arid grasslands and shrublands (Fig.8a, 0.04 0.09 per mm mon ${ }^{-1}$ ), lower VPD (Fig.10b, - $0.1 \sim-0.3$ per kPa) except for DBF sites, and higher LAI (Fig.8d, $0.1 \sim 0.3$ per $\mathrm{m}^{2} \mathrm{~m}^{-2}$ ). $\Omega$ in GLEAM does not capture the increase with precipitation in ENF, DBF, and CRO (Fig.8a, p > 0.01) and has a much stronger negative response to VPD (Fig.8b, -0.3 per $\mathrm{kPa}$ ) than FLUXNET and the other models.

This article is protected by copyright. All rights reserved. 
(a) $\mathrm{d} \Omega / \mathrm{dP}$

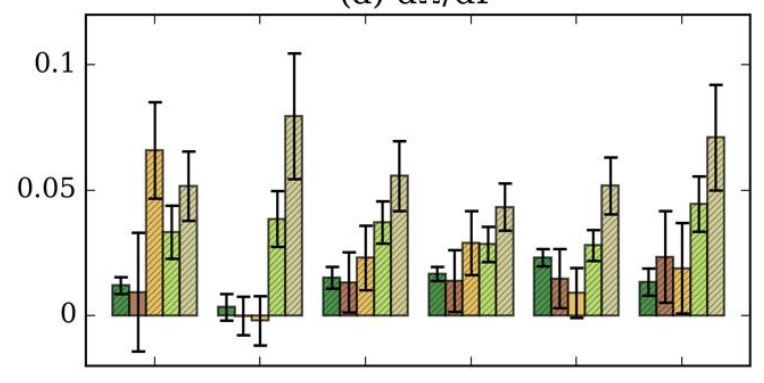

(c) $d \Omega / d u$

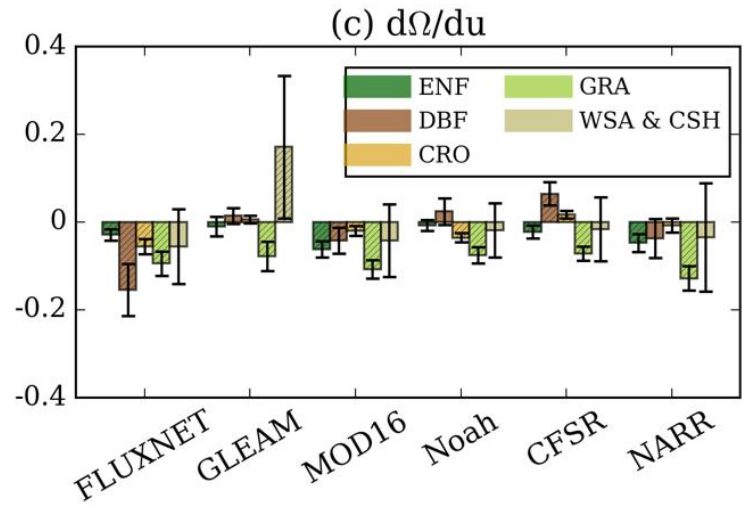

(b) d $\Omega /$ dVPD

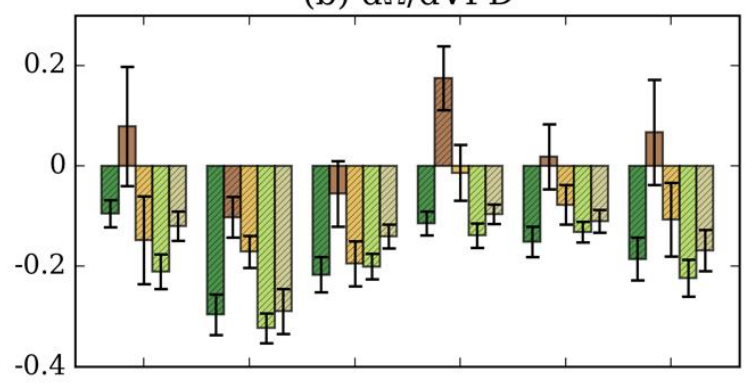

(d) $d \Omega / d L A I$

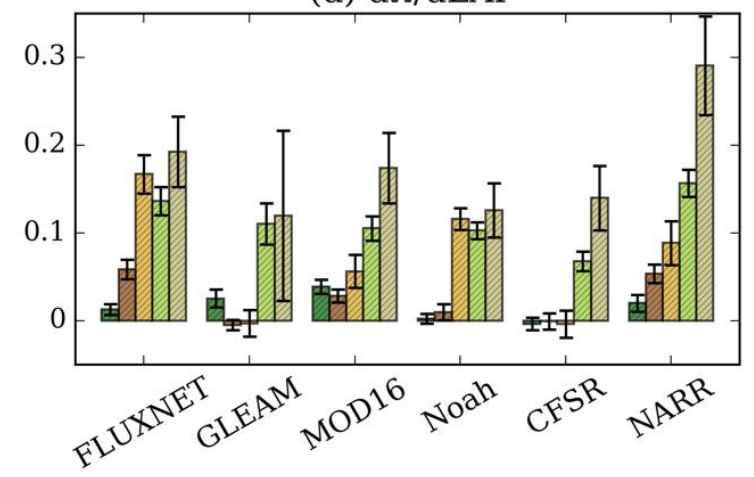

Fig.8 Linear regression slopes of $\Omega$ versus (a) precipitation $\left(\mathrm{P}, \mathrm{mm} \mathrm{d}^{-1}\right)$, (b) VPD (kPa), (c) wind speed $\left(u, \mathrm{~m} \mathrm{~s}^{-1}\right)$, and (d) LAI $\left(\mathrm{m}^{2} \mathrm{~m}^{-2}\right)$ in FLUXNET and the model-based datasets for different vegetation classes. 95\% confidence intervals for regression slopes are indicated by whiskers.

The models generally are in better agreement with FLUXNET in GRA, CSH, and WSA sites. For croplands and forests, the models are less consistent in their responses to wind speed (Fig.8c, Fig.S9ac) and LAI (Fig.8d, Fig.S9d-f) regarding slope sign and magnitude. In terms of slope sign, $\Omega$ in GLEAM and CFSR shows insignificant correlations with wind speed and/or LAI in DBF and CRO, which explains their out-of-phase seasonal variations (Fig.7b, c). In terms of magnitude, the sensitivity of $\Omega$ to wind speed and LAI in the models is generally insignificant or smaller than that in FLUXNET. For instance, in DBF sites, the slope magnitudes in all models are less than 0.1 per $\mathrm{m} \mathrm{s}^{-1}$ for wind speed, and less than 0.06 per $\mathrm{m}^{2} \mathrm{~m}^{-2}$ for LAI.

This article is protected by copyright. All rights reserved. 

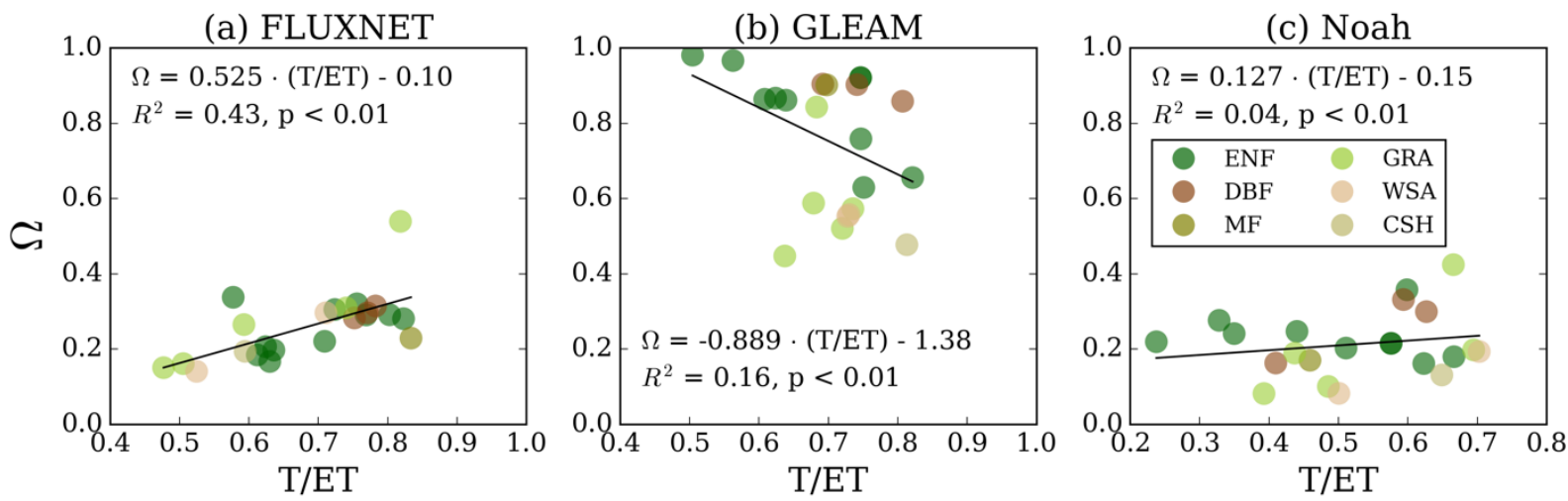

Fig.9 The relationship between $\Omega$ (AET/PET) and the ratio of transpiration to total AET (T/ET) in (a) FLUXNET, (b) GLEAM, and (c) Noah.

The responses of the components of AET to the environmental drivers are very different, so it is very likely that the values and patterns of $\Omega$ are linked with AET partitioning. In FLUXNET, we applied the LAI-based methodology in Wei et al. (2017) to estimate the monthly transpiration to total evapotranspiration ratio (T/ET) at all the natural vegetation sites. A strong positive linear relationship with slope $=0.53$ between site-average $\Omega$ and T/ET is observed (Fig.9a, $\mathrm{R}^{2}=0.43$ ). To explain the differences in model-derived $\Omega$, we also evaluated the $\Omega$-T/ET relationships in the two models that contain separate outputs of transpiration and soil evaporation. In the Noah model, a slight positive relationship with slope $=0.13$ between $\Omega$ and model-derived T/ET is found (Fig.9c, $\left.\mathrm{R}^{2}=0.04\right)$. In contrast, we found a significantly negative relationship between $\Omega$ and model-derived T/ET in GLEAM (Fig.9b, slope $=-0.89, \mathrm{R}^{2}=0.16$ ).

To further understand the uncertainties in the outputs of models and reanalyses, we compared the annual mean $\Omega$ from FLUXNET against the 18 NACP models for 16 overlapping sites (Table S1). Similar to the previous model comparison (Fig.6), Fig.S10 shows a large disagreement between observations and off-line model simulations. As for ENF and MF sites (Fig.S10a, c), the BEPS, ED2, LOTEC, and SSIB 2 models capture the values of observed $\Omega$ reasonably well, while the other models substantially overestimate $\Omega$, with a bias of $0.1 \sim 0.2$. As for WSA sites (Fig.S10f), the ECOSYS,

This article is protected by copyright. All rights reserved. 
ORCHIDEE, and TECO models capture the magnitude of $\Omega$ well, while the other models overestimate the magnitude. As for GRA, DBF and CRO sites, models may overestimate (up to +0.4 ) or underestimate (up to -0.35) $\Omega$. In this comparison, even though additional uncertainties (such as PET estimates and the mismatch of inputs between grid box and site) were precluded as in-situ environmental forcing are used, such huge divergence among the models highlight the inadequate representation of AET processes in the models.

\section{Discussion}

\section{Canopy height is critical to predicting $\Omega$ for forests}

The AET/PET ratio $(\Omega)$, which is closely related to canopy-atmosphere decoupling, decreases with $g_{a}$ (Fig.3). The observed $\Omega$ values are not well explained by LAI at ENF sites (Fig.4d1, $\mathrm{R}^{2}=0.11$ ), as the seasonal variation in leaf phenology for ENF is generally smaller, and canopy height plays a more important role instead (Fig.S5a). $g_{a}$ depends heavily on canopy height through several pathways. First, canopy height and density increase surface roughness, generating higher turbulent exchange and higher $g_{a}$, thus reducing $\Omega$. Second, taller trees usually confront higher wind speed because wind velocity increases with height based on a logarithmic wind profile. We found that $\Omega$ per unit LAI follows a power-law relation with canopy height (Fig.5), where $\Omega$ per unit LAI is sensitive to canopy height when canopy height $<20 \mathrm{~m}$. This observed $\Omega$-canopy height relationship can be used to predict the biophysical constraints on AET as well as to calibrate AET in dense forests.

The formulation of $g_{a}$ was found to be critical for estimating $\Omega$ in forests (Fig.S1 and Text S1). One major difficulty in the derivation of $\Omega$ is determining whether PET should vary with surface characteristics. PET is often estimated by the open water Penman equation and reference crop evapotranspiration (Milly \& Dunne, 2016). Both methods implicitly assume $g_{a}$ is calculated from a smooth surface with low roughness length, which, when applied to forests, tends to underestimate $g_{a}$

This article is protected by copyright. All rights reserved. 
and produce a higher $\Omega$, as demonstrated in Fig.S1. The P-T equation with P-T coefficient $\alpha_{P T}=1.26$ is independent of wind speed and canopy height, which also implicitly suggests $g_{a}$ is calculated with low roughness length (Brutsaert, 1982). Given the inconsistent $g_{a}$ definitions in Eq.1 and Eq.2, these PET methods are likely to produce AET/PET ratios that deviate, in forests, from the concept of decoupling factor (Jarvis \& McNaughton, 1986). Our results confirm the effect of canopy height on $g_{a}$ and highlight the need to incorporate surface characteristics in PET formulation when estimating and interpreting $\Omega$. Our $g_{a}$ formulation, which is adopted from Zilitinkevich (1995), considers the effect of biome, canopy vertical structure, and stability, and provides relatively robust estimates of $\Omega$ across all vegetation types.

In addition to the aerodynamic impact, canopy height is also related to rooting depth and hydraulic functioning and might have physiological impacts on AET and $\Omega$. Taller trees may have deeper roots that provide access to deeper soil moisture, and thus enable them to maintain transpiration rates and withstand drought as in Amazon tropical forests, for example (Nepstad et al., 1994; Giardina et al., 2018). Canopy height is linearly associated with LAI when canopy height $<5 \mathrm{~m}$ (Fig.S8), which tends to increases $g_{s}$ and $\Omega$. However, taller trees are also more vulnerable to atmospheric dryness due to a lower xylem conductivity and a higher risk of cavitation (Novick et al., 2009). Taller trees (> $10 \mathrm{~m}$ ) were found to be more isohydric than shorter vegetation and very sensitive to VPD and stomatal regulation (Konings \& Gentine, 2017). Further reduction in $\Omega$ could arise from the effect of increasing wind speed, which increases VPD by removing saturated air (Kim et al., 2014; Barnard \& Bauerle, 2016) and may potentially reduce $g_{s}$ and dampen $\Omega$. Hence, the biological impact of canopy height may either magnify or offset the aerodynamic impact on AET, depending upon the directions and the relative magnitudes of the two effects. To date, the physical and biological effects of canopy height on AET and $\Omega$ and their balance across various vegetation types remains largely unexplored and may be a worthy avenue for future research.

This article is protected by copyright. All rights reserved. 


\section{The role of $L A I$ in determining $\Omega$}

Our analysis confirms the important role of LAI in regulating $\Omega$ (Fig.4 Column d). LAI is one of the most important variables in simulating AET processes and AET partitioning in climate models and Earth System models (Zeng et al., 2018b; Lian et al., 2018). At a given $g_{a}$ and temperature, $g_{s}$ increases with LAI, enhancing $\Omega$ and the coupling between atmosphere and canopy (Fig.3b). We found that $\Omega$ has a non-linear and saturating response to LAI. When vegetation structure is dense and well-developed (LAI > 3), the increase of $\Omega$ gradually slows at higher LAI values. There are two main reasons for this reduced growth rate of $\Omega$. First, canopy conductance may not necessarily increase with LAI because high LAI can also reduce average absorbed radiation in the canopy (Katul et al., 2012). Second, even though the potential canopy conductance increases linearly with LAI, the $\Omega-g_{s}$ curve starts to reach saturation when $g_{s} / g_{a}>1.5$ (Fig.3b). $\Omega$ is less sensitive to changes in $g_{s}$ when $g_{s}$ is relatively large, and at that point the increase of AET with LAI becomes marginal. When the vegetation fraction is small $(\mathrm{LAI}<3$ ), the contribution of soil evaporation to AET is large (Kelliher et al., 1995), the fraction of net radiation to global radiation is small (Launiainen et al., 2016), and AET is therefore strongly affected by the meteorologically induced stresses. We found that $\Omega$ in GRA, WSA, and CSH sites tends to have low magnitude and large variability under soil water deficit, low radiation load, and high VPD (Fig.4).

Our analysis also reveals that $\Omega$ is more sensitive to LAI at higher aridity (high evaporative demand and/or rainfall deficit) and lower leaf area (Fig.S7). This suggests that $\Omega$ in semi-arid grasslands and savannahs has higher sensitivity to LAI than in forests and croplands. Although this study is based on monthly data, the observed response of $\Omega$ to LAI may be valid over longer time scales. Recent studies indicated that warming temperature may lead to an increase in evaporative demand and drought (e.g., Fu \& Feng, 2014) and have shown a global increase in LAI in semi-arid and arid ecosystems (greening, Zhu et al., 2016) as well as woody plant encroachment into grasslands and savannahs (Knapp et al., 2008). Future changes in $\Omega$ due to increasing aridity and greening, or due to land cover

This article is protected by copyright. All rights reserved. 
change, may have an impact on soil moisture and vegetation productivity, and hence on the water and carbon cycles (Zeng et al., 2018a, 2018b).

\section{Sources of errors in the model-based datasets}

Our results highlight the substantial divergence among the diagnostic, LSM, and reanalysis datasets in the magnitudes of $\Omega$ (Fig.6a). Such large divergence appears to be primarily due to the choice of the PET formulation (Fig.6b). GLEAM and PT-JPL used the P-T approach and produced the lowest PET, because the P-T equation fails to account for the effect of canopy height and temperature on largescale advection (Garratt, 1994). The other models use the P-M approach, which itself is highly variable due to various approaches for $g_{a}$ formulation and additional input uncertainties related to wind speed and vegetation characteristics. PET in forests is hypothesized to be higher due to large roughness; however, we found an increase in PET from forest to grassland in the four P-M based models (Fig.6b). In models using the Noah LSM (Noah, CFSR, and NARR), $C_{z i l}$ is a key parameter used to quantify the dependence of $k B^{-1}$ on $u_{*}$ and determine the thermal roughness length (Eq.7; Weston et al., 2018). $C_{z i l}$ should be very small for tall trees according to observational studies (Chen $\&$ Zhang, 2009; Rigden et al., 2018), suggesting that the default $C_{z i l}=0.1$ for all vegetation types in the Noah model is problematic and could potentially underestimate $g_{a}$ in forests. Our previous findings highlight the need to account for surface roughness in the estimation of AET, particularly in forests. Correctly representing $g_{a}$ in models by appropriately incorporating canopy height and vegetation type is required not only to realistically simulate AET, but also to improve the prediction of sensible heat and land surface temperature, two important variables that determine surface energy exchanges.

This article is protected by copyright. All rights reserved. 
The model departures from observed seasonal patterns of $\Omega$ (Fig.7) are related to the model response of $\Omega$ to climate and vegetation drivers (Fig.8), which is determined by the parameterization of the surface biophysical limitations (e.g., canopy conductance). Our analysis indicates that the modelbased datasets predict the sensitivity of $\Omega$ to driving factors surprisingly well in semi-arid ecosystems. Yet they are not able to capture the observed sensitivity in forests and croplands, especially for wind speed and LAI. In Noah and CFSR, the sensitivities of $\Omega$ to wind speed and LAI at DBF sites are positive and insignificant, respectively (Fig.8c, d), potentially leading to underestimated peaks during the warm season (Fig.7b) and underestimation of summer AET for forests (Xia et al., 2012, 2015). GLEAM does not capture the sensitivity of $\Omega$ to precipitation, LAI, and VPD in forests, which explains the insignificant seasonality of $\Omega$ in their results. We conclude that capturing the response of $\Omega$ to climate and vegetation drivers is critical for better predicting the seasonality of $\Omega$ and AET.

At present, AET partitioning (T/ET) is not captured well by the models (Wei et al., 2017, 2018). Assessing the relationship between $\Omega$ and T/ET in the models may provide new insights into the substantial differences among model-derived $\Omega$. We related the ecosystem-scale $\Omega$ to observed T/ET and found a strong positive linear relationship (Fig.9a). This is mainly because T/ET is also closely linked to LAI and phenology on monthly time scale (Wang et al., 2014; Wei et al., 2017). As LAI increases, canopy conductance increases, resulting in increased transpiration and total evapotranspiration. Meanwhile, available energy transmitted to the soil surface decreases, diminishing soil evaporation. On the other hand, an increase in $g_{s}$ can also result from greater soil conductance (Scott \& Biederman, 2017), which enables plants to access water from deeper soil layers, thereby allowing for continuing transpiration during drought. This can change the total AET level and shift the balance of T/ET, a dynamic which has not been well represented by the ET models. For example, in the GLEAM model, a negative relation between $\Omega$ and T/ET was found (Fig.9b). This is probably due to an overestimation of T/ET in grasslands and savannahs, as GLEAM uses the MODIS MOD44B land cover product to separate the soil and vegetation fraction for each pixel and it does not account for soil evaporation in the vegetated fraction (Miralles et al., 2011). Our analysis highlights This article is protected by copyright. All rights reserved. 
the linkage between canopy-atmosphere decoupling and AET partitioning through the effect of vegetation cover and may provide a useful tool to reconcile observations and large-scale AET datasets. Further observation-based studies should be conducted to investigate the relationship between the levels of $g_{s}$ and T/ET.

The parameterization of surface biophysical limitations is also linked to the PET model structure. For example, soil moisture is sometimes corrected to adjust PET and ensure surface water balance in the models (Yang et al., 2015); vegetation and rooting depth parameters have been tuned to increase AET and match the observed near-surface air temperature in the Climate Forecast System (Saha et al., 2014). Biased PET and $\Omega$ in the models, although they may provide accurate estimates of AET for locations with measurements, may not function well if novel climate and vegetation conditions occur, such as global warming and greening.

\section{Potential Caveats}

There are a few caveats about the practical approximations we used when available observations were less than ideal. Firstly, we applied a correction of the surface energy budget imbalance by adjusting the turbulent fluxes while conserving the Bowen ratio, in order to use the Penman approach. Although this correction of latent heat (AET) may change the magnitude of $\Omega$, it was not likely to change the seasonal variation of $\Omega$ during the warm season. Secondly, when comparing model outputs with observations, we applied a linear interpolation to the FLUXNET daytime measurements and set nighttime AET and PET to zero. This approach did not consider nighttime transpiration, but nonetheless provides an initial estimation that is comparable to model outputs. The $\Omega$ patterns regarding vegetation type are unlikely to be affected by the interpolation (not shown). Thirdly, the satellite-observed LAI may underestimate the site LAI due to the LAI saturation effect and scale

This article is protected by copyright. All rights reserved. 
mismatch (Zhu et al., 2016; Wei et al., 2017). This may cause an overestimation of the sensitivity of $\Omega$ to LAI.

In summary, we evaluated the seasonal dynamics of the AET/PET ratio $(\Omega)$ at the North American FLUXNET sites across various biomes and climates and from large-scale models at the collocated grids. We found that the importance of vegetation vertical structure in forests cannot be understated, since canopy height largely determines $g_{a}$ and canopy-atmosphere decoupling. As $g_{a}$ is fundamentally linked to sensible heat and energy balance, calibration and incorporation of canopy height in the representation of the biophysical limitations can potentially improve the predictions of the water and energy balances. Our results emphasize that LAI is central to the estimation of $\Omega$ and can be quantitatively linked to AET partitioning, which is largely determined by LAI. We found substantial differences between observed $\Omega$ and model-based $\Omega$ in terms of their magnitudes and the patterns across vegetation types. These differences are closely related to the way these models are built to estimate PET, to represent the $\Omega$ responses to the environmental drivers, and to partition transpiration and soil evaporation across vegetation types. More efforts are needed to identify errors in the model responses to the drivers and to understand the sources of uncertainties. Continuous satellite monitoring of vegetation cover and plant water stress will also contribute to an improved understanding of how AET interacts with climate and vegetation and will facilitate progress toward understanding the response of water availability to climate change.

\section{Acknowledgements}

This research was sponsored by NASA under grant NNX14AB36A. We acknowledge the members of the FLUXNET community, especially the AmeriFlux network, for their help in providing the La Thuile dataset (http://fluxnet.fluxdata.org/data/la-thuile-dataset/). We acknowledge institutions and projects for free access to relevant datasets: the Oak Ridge National Laboratory Distributed Active

This article is protected by copyright. All rights reserved. 
Archive Center (Fixed Sites Subsets Tool: https://modis.ornl.gov/sites/), the Global Land-surface Evaporation: The Amsterdam Methodology, the Priestley and Taylor Jet Propulsion Laboratory model, the Phase 2 of the North American Land Data Assimilation System, the Climate Forecast System Reanalysis, the North America Regional Reanalysis, the MOderate-Resolution Imaging Spectroradiometer global database, and the North American Carbon Program Site-Level Interim Synthesis team. We thank Nathaniel Chaney at Duke University for the pre-processing of the eddy covariance data. Finally, we deeply thank the three anonymous reviewers for their constructive criticisms that improved the work substantially.

\section{References}

Allen, R. G., Pereira, L. S., Raes, D., \& Smith, M. (1998). Crop evapotranspiration-Guidelines for computing crop water requirements-FAO Irrigation and drainage paper 56. Rome: FAO.

Allen, R. G., \& Pereira, L. S. (2009). Estimating crop coefficients from fraction of ground cover and height. Irrigation Science, 28, 17-34.

Anderegg, W. R. L., Klein, T., Bartlett, M., Sack, L., Pellegrini, A. F. A., Choat, B., \& Jansen, S. (2016). Meta-analysis reveals that hydraulic traits explain cross-species patterns of droughtinduced tree mortality across the globe. Proceedings of the National Academy of Sciences, 113, $5024-5029$.

Anderson, M. C., Norman, J. M., Mecikalski, J. R., Otkin, J. A., \& Kustas, W. P. (2007). A climatological study of evapotranspiration and moisture stress across the continental United States based on thermal remote sensing: 2. Surface moisture climatology. Journal of Geophysical Research, 112.

Anderson, M. C., Hain, C., Wardlow, B., Pimstein, A., Mecikalski, J. R., \& Kustas, W. P. (2011). Evaluation of drought indices based on thermal remote sensing of evapotranspiration over the continental United States. Journal of Climate, 24, 2025-2044.

Barnard, D. M., \& Bauerle, W. L. (2016). Seasonal variation in canopy aerodynamics and the sensitivity of transpiration estimates to wind velocity in broadleaved deciduous species. Journal of Hydrometeorology, 17, 3029-3043.

Brutsaert, W. (1982). The Surface Roughness Parameterization. In: Evaporation into the atmosphere: theory, history and applications (pp. 113-127). Dordrecht: Springer Science+Business Media.

Caylor, K. K., Shugart, H. H., \& Rodríguez-Iturbe, I. (2005). Tree canopy effects on simulated water stress in southern african savannas. Ecosystems, 8, 17-32.

This article is protected by copyright. All rights reserved. 
Chen, F., Mitchell, K., Schaake, J. C., Xue, Y., Pan, H. L., Koren, V., et al. (1996). Modeling of land surface evaporation by four schemes and comparison with FIFE observations. Journal of Geophysical Research: Atmospheres, 101, 7251-7268.

Chen, F., Janjić, Z., \& Mitchell, K. (1997). Impact of atmospheric surface-layer parameterizations in the new land-surface scheme of the NCEP mesoscale Eta model. Boundary-Layer Meteorology, 85, 391-421.

Chen, F., \& Zhang, Y. (2009). On the coupling strength between the land surface and the atmosphere: From viewpoint of surface exchange coefficients. Geophysical Research Letters, 36, L10404.

Chu, H., Baldocchi, D. D., Poindexter, C., Abraha, M., Desai, A. R., Bohrer, G., et al. (2018). Temporal dynamics of aerodynamic canopy height derived from eddy covariance momentum flux data across North American flux networks. Geophysical Research Letters, 45.

De Kauwe, M. G. D., Medlyn, B. E., Knauer, J., \& Williams, C. A. (2017). Ideas and perspectives: how coupled is the vegetation to the boundary layer? Biogeosciences, 14, 4435-4453.

D'Odorico, P., Davis, K. F., Rosa, L., Carr, J. A., Chiarelli, D., Dell'Angelo, J., et al. (2018). The global food-Energy-Water Nexus. Reviews of Geophysics, 56, 456-531.

Donohue, R. J., Roderick, M. L., \& McVicar, T. R. (2010). Can dynamic vegetation information improve the accuracy of Budyko's hydrological model? Journal of Hydrology, 390, 23-34.

Dufresne, J. L., Foujols, M. A., Denvil, S., Caubel, A., Marti, O., Aumont, O., et al. (2013). Climate change projections using the IPSL-CM5 Earth System Model: from CMIP3 to CMIP5. Climate Dynamics, 40, 2123-2165.

Ek, M. B., Mitchell, K. E., Lin, Y., Rogers, E., Grunmann, P., Koren, V., et al. (2003). Implementation of Noah land surface model advances in the National Centers for Environmental Prediction operational mesoscale Eta model. Journal of Geophysical Research: Atmospheres, $108,8851$.

Field, C. B., Jackson, R. B., \& Mooney, H. A. (1995). Stomatal responses to increased CO2: implications from the plant to the global scale. Plant, Cell \& Environment, 18, 1214-1225.

Fisher, J. B., Tu, K. P., \& Baldocchi, D. D. (2008). Global estimates of the land-atmosphere water flux based on monthly AVHRR and ISLSCP-II data, validated at 16 FLUXNET sites. Remote Sensing of Environment, 112, 901-919.

Fisher, J. B., Melton, F., Middleton, E., Hain, C., Anderson, M. C., Allen, R. G., et al. (2017). The future of evapotranspiration: Global requirements for ecosystem functioning, carbon and climate feedbacks, agricultural management, and water resources. Water Resources Research, 53, 26182626.

Fu, Q., \& Feng, S. (2014). Responses of terrestrial aridity to global warming. Journal of Geophysical Research: Atmospheres, 119, 7863-7875.

Garratt, J. R. (1994). Evaporation. In: The Atmospheric Boundary Layer (pp. 125-135). Cambridge: Cambridge University Press.

This article is protected by copyright. All rights reserved. 
Gedney, N., Cox, P. M., Betts, R. A., Boucher, O., Huntingford, C., \& Stott, P. A. (2006). Detection of a direct carbon dioxide effect in continental river runoff records. Nature, 439, 835-838.

Giardina, F., Konings, A. G., Kennedy, D., Alemohammad, S. H., Oliveira, R. S., Uriarte, M., \& Gentine, P. (2018). Tall Amazonian forests are less sensitive to precipitation variability. Nature Geoscience, 11, 405-409.

Greve, P., Orlowsky, B., Mueller, B., Sheffield, J., Reichstein, M., \& Seneviratne, S. I. (2014). Global assessment of trends in wetting and drying over land. Nature Geoscience, 7, 716-721.

Jackson, R. D., Idso, S. B., Reginato, R. J., \& Pinter, P. J., Jr. (1981). Canopy temperature as a crop water stress indicator. Water Resources Research, 17, 1133-1138.

Jarvis, P. G., \& McNaughton, K. G. (1986). Stomatal control of transpiration: scaling up from leaf to region. In: Advances in Ecological Research (Vol. 15, pp. 1-49). London: Academic Press.

Jung, M., Reichstein, M., Ciais, P., Seneviratne, S. I., Sheffield, J., Goulden, M. L., et al. (2010). Recent decline in the global land evapotranspiration trend due to limited moisture supply. Nature, 467, 951-954.

Kang, S., Gu, B., Du, T., \& Zhang, J. (2003). Crop coefficient and ratio of transpiration to evapotranspiration of winter wheat and maize in a semi-humid region. Agricultural Water Management, 59, 239-254.

Katul, G. G., PALMROTH, S., \& Oren, R. (2009). Leaf stomatal responses to vapour pressure deficit under current and $\mathrm{CO} 2$-enriched atmosphere explained by the economics of gas exchange. Plant, Cell \& Environment, 32, 968-979.

Katul, G. G., Oren, R., Manzoni, S., Higgins, C., \& Parlange, M. B. (2012). Evapotranspiration: A process driving mass transport and energy exchange in the soil-plant-atmosphere-climate system. Reviews of Geophysics, 50, RG3002.

Knauer, J., Zaehle, S., Medlyn, B. E., Reichstein, M., Williams, C. A., Migliavacca, M., et al. (2018). Towards physiologically meaningful water-use efficiency estimates from eddy covariance data. Global Change Biology, 24, 694-710.

Kay, J. E., Deser, C., Phillips, A., Mai, A., Hannay, C., Strand, G., et al. (2015). The Community Earth System Model (CESM) large ensemble project: A community resource for studying climate change in the presence of internal climate variability. Bulletin of the American Meteorological Society, 96, 1333-1349.

Kelliher, F. M., Leuning, R., Raupach, M. R., \& Schulze, E. D. (1995). Maximum conductances for evaporation from global vegetation types. Agricultural and Forest Meteorology, 73, 1-16.

Kim, D., Oren, R., Oishi, A. C., Hsieh, C.-I., Phillips, N., Novick, K. A., \& Stoy, P. C. (2014). Sensitivity of stand transpiration to wind velocity in a mixed broadleaved deciduous forest. Agricultural and Forest Meteorology, 187, 62-71.

This article is protected by copyright. All rights reserved. 
Knapp, A. K., Briggs, J. M., Collins, S. L., Archer, S. R., Bret-Harte, M. S., Ewers, B. E., et al. (2008). Shrub encroachment in North American grasslands: shifts in growth form dominance rapidly alters control of ecosystem carbon inputs. Global Change Biology, 14, 615-623.

Konings, A. G., \& Gentine, P. (2017). Global variations in ecosystem-scale isohydricity. Global Change Biology, 23, 891-905.

Kottek, M., Grieser, J., Beck, C., Rudolf, B., \& Rubel, F. (2006). World Map of the Köppen-Geiger climate classification updated. Meteorologische Zeitschrift, 15, 259-263.

Launiainen, S., Katul, G. G., Kolari, P., Lindroth, A., Lohila, A., Aurela, M., et al. (2016). Do the energy fluxes and surface conductance of boreal coniferous forests in Europe scale with leaf area? Global Change Biology, 22, 4096-4113.

Lawrence, D. M., Thornton, P. E., Oleson, K. W., \& Bonan, G. B. (2007). The partitioning of evapotranspiration into transpiration, soil evaporation, and canopy evaporation in a GCM: impacts on land-atmosphere interaction. Journal of Hydrometeorology, 8, 862-880.

Lian, X., Piao, S., Huntingford, C., Li, Y., Zeng, Z., Wang, X., et al. (2018). Partitioning global land evapotranspiration using CMIP5 models constrained by observations. Nature Climate Change, 8 , 640-646.

Liu, C., Sun, G., McNulty, S. G., Noormets, A., \& Fang, Y. (2017). Environmental controls on seasonal ecosystem evapotranspiration/potential evapotranspiration ratio as determined by the global eddy flux measurements. Hydrology and Earth System Sciences, 21, 311-322.

Mallick, K., Trebs, I., Boegh, E., Giustarini, L., Schlerf, M., Drewry, D. T., et al. (2016). Canopyscale biophysical controls of transpiration and evaporation in the Amazon Basin. Hydrology and Earth System Sciences, 20, 4237-4264.

Martens, B., Gonzalez Miralles, D., Lievens, H., van der Schalie, R., de Jeu, R. A., Fernández-Prieto, D., et al. (2017). GLEAM v3 : satellite-based land evaporation and root-zone soil moisture. Geoscientific Model Development, 10, 1903-1925.

Mesinger, F., DiMego, G., Kalnay, E., Mitchell, K., Shafran, P. C., Ebisuzaki, W., et al. (2006). North American Regional Reanalysis. Bulletin of the American Meteorological Society, 87, 343-360.

Milly, P. C. D., \& Dunne, K. A. (2016). Potential evapotranspiration and continental drying. Nature Climate Change, 6, 946-949.

Miralles, D. G., Holmes, T. R. H., De Jeu, R. A. M., Gash, J. H., Meesters, A. G. C. A., \& Dolman, A. J. (2011). Global land-surface evaporation estimated from satellite-based observations. Hydrology and Earth System Sciences, 15, 453-469.

Monteith, J. L. (1965). Evaporation and environment. Symposia of the Society for Experimental Biology, 19, 205-234.

Mu, Q., Zhao, M., \& Running, S. W. (2011). Improvements to a MODIS global terrestrial evapotranspiration algorithm. Remote Sensing of Environment, 115, 1781-1800.

This article is protected by copyright. All rights reserved. 
Mueller, B., Hirschi, M., Jiménez, C., Ciais, P., Dirmeyer, P. A., Dolman, A. J., et al. (2013). Benchmark products for land evapotranspiration: LandFlux-EVAL multi-data set synthesis. Hydrology and Earth System Sciences, 17, 3707-3720.

Myneni, R., Knyazikhin, Y., \& Park, T. (2015). MOD15A2H MODIS Leaf Area Index/FPAR 8-Day L4 Global 500m SIN Grid V006. NASA EOSDIS Land Processes DAAC. http://doi.org/10.5067/MODIS/MOD15A2H.006.

Nepstad, D. C., de Carvalho, C. R., Davidson, E. A., Jipp, P. H., Lefebvre, P. A., Negreiros, G. H., et al. (1994). The role of deep roots in the hydrological and carbon cycles of Amazonian forests and pastures. Nature, 372, 666-669.

Novick, K. A., Oren, R., Stoy, P., Juang, J.-Y., Siqueira, M., \& Katul, G. G. (2009). The relationship between reference canopy conductance and simplified hydraulic architecture. Advances in Water Resources, 32, 809-819.

Novick, K. A., Miniat, C. F., \& Vose, J. M. (2016a). Drought limitations to leaf-level gas exchange: results from a model linking stomatal optimization and cohesion-tension theory. Plant, Cell \& Environment, 39, 583-596.

Novick, K. A., Ficklin, D. L., Stoy, P. C., Williams, C. A., Bohrer, G., Oishi, A. C., et al. (2016b). The increasing importance of atmospheric demand for ecosystem water and carbon fluxes. Nature Climate Change, 6, 1023-1027.

Oki, T., \& Kanae, S. (2006). Global hydrological cycles and world water resources. Science, 313, $1068-1072$.

Ohta, T., Maximov, T. C., Dolman, A. J., Nakai, T., van der Molen, M. K., Kononov, A. V., et al. (2008). Interannual variation of water balance and summer evapotranspiration in an eastern Siberian larch forest over a 7-year period (1998-2006). Agricultural and Forest Meteorology, 148, 1941-1953.

ORNL DAAC (2018). MODIS and VIIRS Land Products Fixed Sites Subsetting and Visualization Tool. Oak Ridge National Laboratory Distributed Active Archive Center, Oak Ridge, Tennessee, USA. Accessed Nov, 2018. Subset obtained for MOD15A2H and MOD16A2 product at various sites in Spatial Range: N=50N, S=25N, E=50W, W=120W, time period: 2000-02-18 to 2007-1231. https://doi.org/10.3334/ORNLDAAC/1567.

Penman, H. L. (1948). Natural evaporation from open water, bare soil and grass. In: Proceedings of the Royal Society of London Series A (Vol. 193, pp. 120-145). The Royal Society.

Peng, L., Li, D., \& Sheffield, J. (2018). Drivers of variability in atmospheric evaporative demand: multiscale spectral analysis based on observations and physically based modeling. Water Resources Research, 54, 3510-3529.

Polhamus, A., Fisher, J. B., \& Tu, K. P. (2013). What controls the error structure in evapotranspiration models? Agricultural and Forest Meteorology, 169, 12-24.

Ponce-Campos, G. E., Moran, M. S., Huete, A., Zhang, Y., Bresloff, C., Huxman, T. E., et al. (2013). Ecosystem resilience despite large-scale altered hydroclimatic conditions. Nature, 494, 349-352.

This article is protected by copyright. All rights reserved. 
Priestley, C., \& Taylor, R. J. (1972). On the assessment of surface heat flux and evaporation using large-scale parameters. Monthly Weather Review, 100, 81-92.

Raupach, M. R. (1994). Simplified expressions for vegetation roughness length and zero-plane displacement as functions of canopy height and area index. Boundary-Layer Meteorology, 71, 211-216.

Ricciuto, D. M., Schaefer, K., Thornton, P. E., Davis, K., Cook, R. B., Liu, S., et al. (2013). NACP Site: Terrestrial Biosphere Model and Aggregated Flux Data in Standard Format. Oak Ridge National Laboratory Distributed Active Archive Center, Oak Ridge, Tennessee, USA. http://dx.doi.org/10.3334/ORNLDAAC/1183.

Rigden, A., Li, D., \& Salvucci, G. D. (2018). Dependence of thermal roughness length on friction velocity across land cover types: A synthesis analysis using AmeriFlux data. Agricultural and Forest Meteorology, 249, 512-519.

Ritchie, J. T. (1998). Soil water balance and plant water stress. In: Tsuji, G. Y., Hoogenboom, G., Thornton, P. K. (Eds.), Understanding Options for Agricultural Production (Vol. 7, pp. 41-54). Dordrecht: Springer.

Running, S., \& Mu., Q. (2017). MOD16A2 MODIS/Terra Net Evapotranspiration 8-Day L4 Global $500 \mathrm{~m}$ SIN Grid V006. NASA EOSDIS Land Processes DAAC. https://doi.org/10.5067/MODIS/MOD16A2.006.

Ryu, Y., Baldocchi, D. D., Ma, S., \& Hehn, T. (2008). Interannual variability of evapotranspiration and energy exchange over an annual grassland in California. Journal of Geophysical Research, $113,424$.

Saha, S., Wang, J., Tripp, P., Behringer, D., Ek, M. B., Meng, J., et al. (2014). The NCEP Climate Forecast System Version 2. Journal of Climate, 27, 2185-2208.

Saha, S., Moorthi, S., Pan, H. L., Wu, X., Wang, J., Nadiga, S., et al. (2010). The NCEP Climate Forecast System Reanalysis. Bulletin of the American Meteorological Society, 91, 1015-1058.

Schaake, J. C., Koren, V. I., Duan, Q. Y., Mitchell, K., \& Chen, F. (1996). Simple water balance model for estimating runoff at different spatial and temporal scales. Journal of Geophysical Research: Atmospheres, 101, 7461-7475.

Scott, R. L., \& Biederman, J. A. (2017). Partitioning evapotranspiration using long-term carbon dioxide and water vapor fluxes. Geophysical Research Letters, 44, 6833-6840.

Sheffield, J., Wood, E. F., \& Roderick, M. L. (2012). Little change in global drought over the past 60 years. Nature, 491, 435-438.

Shukla, J., \& Mintz, Y. (1982). Influence of land-surface evapotranspiration on the Earth's climate. Science, 215, 1498-1501.

Sperry, J. S., Venturas, M. D., Anderegg, W. R. L., Mencuccini, M., Mackay, D. S., Wang, Y., \& Love, D. M. (2016). Predicting stomatal responses to the environment from the optimization of photosynthetic gain and hydraulic cost. Plant, Cell \& Environment, 40, 816-830.

This article is protected by copyright. All rights reserved. 
Sun, J., \& Mahrt, L. (1995). Determination of surface fluxes from the surface radiative temperature. Journal of the Atmospheric Sciences, 52, 1096-1106.

Twine, T. E., Kustas, W. P., Norman, J. M., Cook, D. R., Houser, P. R., Meyers, T. P., et al. (2000). Correcting eddy-covariance flux underestimates over a grassland. Agricultural and Forest Meteorology, 103, 279-300.

van Beek, L. P. H., Wada, Y., \& Bierkens, M. F. P. (2011). Global monthly water stress: 1. Water balance and water availability. Water Resources Research, 47, W07517.

Verma, S. B. (1989). Aerodynamic resistances to transfers of heat, mass and momentum. In: Black, T. A., Spittlehouse, D. L., Novak, M. D., Price, D. T. (Eds.), Estimation of Areal Evapotranspiration (pp. 13-20). IAHS Press.

Wang, K., \& Dickinson, R. E. (2012). A review of global terrestrial evapotranspiration: Observation, modeling, climatology, and climatic variability. Reviews of Geophysics, 50, RG2005.

Wang, L., Good, S. P., \& Caylor, K. K. (2014). Global synthesis of vegetation control on evapotranspiration partitioning. Geophysical Research Letters, 41, 6753-6757.

Wei, Z., Yoshimura, K., Wang, L., Miralles, D. G., Jasechko, S., \& Lee, X. (2017). Revisiting the contribution of transpiration to global terrestrial evapotranspiration. Geophysical Research Letters, 44, 2792-2801.

Wei, Z., Lee, X., Wen, X., \& Xiao, W. (2018). Evapotranspiration partitioning for three agroecosystems with contrasting moisture conditions: a comparison of an isotope method and a twosource model calculation. Agricultural and Forest Meteorology, 252, 296-310.

Weston, M., Chaouch, N., Valappil, V., Temimi, M., Ek, M. B., \& Zheng, W. (2018). Assessment of the sensitivity to the thermal roughness length in Noah and Noah-MP land surface model using WRF in an arid region. Pure and Applied Geophysics, 41, 1-17.

Williams, C. A., Reichstein, M., Buchmann, N., Baldocchi, D. D., Beer, C., Schwalm, C., et al. (2012). Climate and vegetation controls on the surface water balance: Synthesis of evapotranspiration measured across a global network of flux towers. Water Resources Research, 48, W06523.

Wohlfahrt, G., Haslwanter, A., Hörtnagl, L., Jasoni, R. L., Fenstermaker, L. F., Arnone, J. A., III, \& Hammerle, A. (2009). On the consequences of the energy imbalance for calculating surface conductance to water vapour. Agricultural and Forest Meteorology, 149, 1556-1559.

Wullschleger, S. D., Wilson, K. B., \& Hanson, P. J. (2000). Environmental control of whole-plant transpiration, canopy conductance and estimates of the decoupling coefficient for large red maple trees. Agricultural and Forest Meteorology, 104, 157-168.

Xia, Y., Mitchell, K., Ek, M. B., Sheffield, J., Cosgrove, B., Wood, E. F., et al. (2012). Continental-scale water and energy flux analysis and validation for the North American Land Data Assimilation System project phase 2 (NLDAS-2): 1. Intercomparison and application of model products. Journal of Geophysical Research: Atmospheres, 117, D03109.

This article is protected by copyright. All rights reserved. 
Xia, Y., Hobbins, M. T., Mu, Q., \& Ek, M. B. (2015). Evaluation of NLDAS-2 evapotranspiration against tower flux site observations. Hydrological Processes, 29, 1757-1771.

Yang, R., Ek, M. B., \& Meng, J. (2015). Surface water and energy budgets for the Mississippi river basin in three NCEP reanalyses. Journal of Hydrometeorology, 16, 857-873.

Zeng, Z., Piao, S., Li, L. Z. X., Wang, T., Ciais, P., Lian, X., et al. (2018a). Impact of Earth greening on the terrestrial water cycle. Journal of Climate, 31, 2633-2650.

Zeng, Z., Peng, L., \& Piao, S. (2018b). Response of terrestrial evapotranspiration to Earth's greening. Current Opinion in Environmental Sustainability, 33, 9-25.

Zhang, K., Kimball, J. S., Nemani, R. R., Running, S. W., Hong, Y., Gourley, J. J., \& Yu, Z. (2015). Vegetation greening and climate change promote multidecadal rises of global land evapotranspiration. Scientific Reports, 5, 15956.

Zhu, Z., Piao, S., Myneni, R. B., Huang, M., Zeng, Z., Canadell, J. G., et al. (2016). Greening of the Earth and its drivers. Nature Climate Change, 6, 791-795.

Zilitinkevich, S. S. (1995). Non-local turbulent transport: Pollution dispersion aspects of coherent structure of convective flows. In: Power, H., Moussiopoulos, N., Brebbia, C. A. (Eds.), Air pollution III. Volume I. Air pollution theory and simulation (pp. 53-60). Computational Mechanics Publications.

\section{Supporting Information}

Additional Supporting Information may be found in the online version of this article.

Data S1 DataS1_annual_mean_omega_fluxnet_2000-2007.csv.

Text S1 $\Omega$ dependence on the formulation of aerodynamic conductance.

Figure S1 Annual mean $\Omega$ calculated using four $g_{a}$ methods grouped by the vegetation types.

Text S2 Other factors affecting $\Omega$ estimates.

Figure S2 Annual mean $\Omega$ calculated from raw data with energy balance non-closure (black) and from adjusted data using Bowen ratio method (blue) grouped by the vegetation types.

Figure S3 Annual time series of $\Omega$ at the 28 Ameriflux sites grouped by the vegetation types.

Figure S4 Seasonality of $g_{s}$ at the 28 Ameriflux sites grouped by the K-G climate classes.

This article is protected by copyright. All rights reserved. 
Figure S5 Seasonality of $g_{a}$ at the 28 Ameriflux sites grouped by the vegetation classes.

Figure S6 The relationships between monthly $\Omega$ and monthly (a) $T_{a}$ : air temperature (K), (b) $R g$ : global radiation $\left(\mathrm{W} \mathrm{m}^{-2}\right)$ for different vegetation classes.

Figure S7 The sensitivity of $\Omega$ to LAI vs site-average (a) monthly total precipitation, (b) LAI, (c) $T_{a}$, and (d) VPD, with marker shape and color coded with vegetation type.

Figure S8 The relationship between LAI and canopy height (h) color coded with vegetation type.

Figure S9 The relationships between monthly $\Omega$ and (a), (b), (c) wind speed ( $\left.u, \mathrm{~m} \mathrm{~s}^{-1}\right)$, and (d) (e) (f) LAI $\left(\mathrm{m}^{2} \mathrm{~m}^{-2}\right)$ for ENF, DBF, and CRO in the FLUXNET data and the model-based datasets.

Table S1 The 16 overlapping sites between NACP site-level synthesis and the 28 sites selected in this study.

Figure S10 Annual mean $\Omega$ in FLUXNET and the 18 NACP models for the 16 overlapping sites grouped by the six vegetation types.

This article is protected by copyright. All rights reserved. 